\title{
Microstructure and Chemical Composition of Particles from Small-scale Gas Flaring
}

\author{
Olga Popovicheva ${ }^{1 *}$, Mikhail Timofeev ${ }^{1}$, Natalia Persiantseva ${ }^{1}$, Melina A. Jefferson ${ }^{2}$, \\ Matthew Johnson ${ }^{2}$, Steven N. Rogak ${ }^{3}$, Alberto Baldelli ${ }^{3}$ \\ ${ }^{1}$ Skobeltsyn Institute of Nuclear Physics, Lomonosov Moscow State University, 119991 Moscow, Russia \\ ${ }^{2}$ Department of Mechanical and Aerospace Engineering, Carleton University, Ottawa, ON, K1S 5B6, Canada \\ ${ }^{3}$ Department of Mechanical Engineering, University of British Columbia, Vancouver, BC, V6T 1Z4, Canada
}

\begin{abstract}
Among globally relevant combustion sources, such as diesel emission and biomass burning, gas flaring remains the most uncertain. In this study, small-scale turbulent gas flaring was used to characterize particulate emissions produced under different operating conditions, such as various burner diameters and exit velocities. The composition of the fuel was also varied by modifying the percentage of methane, ethane, propane, butane, $\mathrm{N}_{2}$, and $\mathrm{CO}_{2}$, which are the predominant constituents in the upstream oil and gas industry. A broad suite of physical, chemical, and microscopic techniques was employed for analysis, and scanning electron microscopy showed the generated soot agglomerates to be composed of primary spherules that were $30 \pm 10 \mathrm{~nm}$ in diameter. Additionally, high-resolution transmission electron microscopy, used to determine the length, tortuosity, and separation of individual graphene fringes on the primary particles, revealed a fullerenic, multiple-nuclei internal structure. Single-particle analysis revealed the dominance of elemental carbon vs. oxidized and metal-contaminated particles, and infrared spectroscopy showed the presence of alkanes and aromatics with oxygenated compounds. Intercomparing the microstructure and the composition, we also concluded that the vast majority of particles are hydrophobic.
\end{abstract}

Keywords: Gas flaring; Soot; Fullerenic internal structure; Graphitic content; Elemental composition; Hygroscopicity.

\section{INTRODUCTION}

Combustion emissions are an important source of radiatively and chemically active aerosols, affecting the earth's radiation energy balance, climate, and air quality. A large amount of air pollution is produced worldwide by annual burning of billions of tons of fossil fuel and biomass (Bond et al., 2013). Globally, major sources of aerosols emissions in the atmosphere are residential wood burning $(38 \%)$, transport sectors $(26 \%)$, and wildfires $(28 \%)$. Flaring and agricultural waste burning are thought to contribute less than $3 \%$ and $4 \%$, respectively (Stohl et al., 2013), while north of $60^{\circ} \mathrm{N}$, biomass burning (58\%) and flaring emissions (33\%) are the most important sources. Recent efforts have sought to develop better flare black carbon inventories based on comprehensive simulation of air pollution in the Arctic (Huang et al., 2015) as well as consideration of globally varying flare gas heating values (Huang and $\mathrm{Fu}, 2016$ ). A global gas flaring black carbon emission rate dataset from

\footnotetext{
${ }^{*}$ Corresponding author.

E-mail address: polga@mics.msu.su
}

1994 to 2012 (Huang and Fu, 2016) was combined with emission factor data obtained at the laboratory scale (McEwen and Johnson, 2012). Only a few recent studies have measured gas flare emissions in a real-world setting (Weyant et al., 2016; Conrad and Johnson, 2017; Gvakharia et al., 2017) and none have reported particle characteristics at microscopic level.

Carbonaceous aerosol nanostructure varies significantly depending on the burning practice, the combustion phase, and the fuel type. High-temperature incomplete combustion of hydrocarbon fuels produces soot agglomerates (Baumgardner et al., 2012) with a high surface-area to-mass ratio (Tumolva et al., 2010). They are formed by the coagulation of primary particles originated from the decomposition of fuel precursors followed by mass growth at the flame (Wang, 2011). Soot generated from overall lean (oxygen-rich) combustion and high temperatures are made of agglomerated primary particles with sizes between 10 and $30 \mathrm{~nm}$ (Sadezky et al., 2005). The internal soot structure is defined by the size, shape, and organization of the graphene layers, observable as "fringes" using High Resolution Transmission Electron Microscopy (HRTEM) (Chen et al., 2005; Demirdjian et al., 2007). The analysis of lattice fringes shows the impact of fuel composition and combustion 
temperature on the internal structure of elemental carbon, which can be defined as graphitic, fullerenic, or amorphous (Hays and Vander Wal, 2007; Trivanovic, 2019). Soot produced by high-temperature combustion in burners, engines, and ovens show perturbed graphitic or turbostratic onion like structure (Clague et al., 1999), which has a size of about $3 \mathrm{~nm}$ with interlayer distances of about $3.5 \AA$ (Sadezky et al., 2005).

The degree of order in the soot nanostructure can also be evaluated using a Raman spectroscopy (Rebelo et al., 2016; Baldelli and Rogak, 2019). Morphological analysis demonstrates soot particles from different fuels exhibited different concentrations of amorphous carbon and structural defects (Chen et al., 2019).

Scanning Electron Microscopy (SEM) coupled with Energy-dispersive X-ray (EDX) spectroscopy can be used to characterize the size, the morphology, and the composition of particulates (Chen et al., 2005; Popovicheva et al., 2012, 2015b). Besides carbonaceous material as a principal component of soot, inorganic species are generated in the form of salts or oxides in metal-bearing diesel particles, also derived due to the engine wear (Miller et al., 2007; Bladt et al., 2012). Advanced single particle analyses reveal soot and fly ashes in the diesel engine exhaust in relation to fuel and lubrication oil composition (Popovicheva et al., 2014). Okada and Hitzenberger (2001) differentiated carbonaceous aerosols with respect to their ability to uptake water into hygroscopic and water-insoluble particles, with and without water-soluble inclusions respectively. The influence of oxygen and sulfur concentrations on the ability of soot to uptake water is proposed as a method for categorizing the engine-generated individual particles (Kireeva et al., 2009). The fractionation of elemental composition into chain soot agglomerates, irregular internally mixed soot, and particles of mineral morphology has allowed the separation of particles as hydrophobic, hydrophilic, and hygroscopic.

According to the hydrogen-abstraction-carbon-addition (HACA) mechanism of soot formation, the role of aromatic radicals resulting from localized $\pi$-electron structures is in the particle nucleation and subsequent mass growth (Wang, 2011). Aromatic radicals provide the strong binding forces for forming the six-membered benzenoid rings of polycyclic aromatic hydrocarbons (PAHs) of graphitic core. Nonaromatic (aliphatic) functionalities and reactive oxygencontaining sites may influence the surface growth and disorder the soot structure (Cain et al., 2010). Oxygenated fragments could also undergo recombination and polymerization reactions to form larger macromolecular carbonaceous material, offering the second pathway for soot formation by biomass burning (Fitzpatrick et al., 2007). Organic matter can be derived from either soot generation pathway from small molecules such as acetylene, or can be produced from unburned volatiles released from the fuel and adsorbed during the cooling and dispersion process (Ross et al., 2005).

Functionalization of particles is attributed to various classes of organic oxygen, hydrogen, and nitrogencontaining compounds in laboratory-produced soot (Daly and Horn, 2009) and ambient aerosols (Coury and Dillner, 2009; Russell et al., 2011). Soot extracted in the post-flame region contain significant amounts of aliphatic components relative to aromatics, as characterized by Fourier Transform Infrared (FTIR) spectroscopy (Cain et al., 2010). Speciation of soot chemical composition is critical for understanding the atmospheric reactivity and hygroscopicity. Thus, aliphatic $\mathrm{C}-\mathrm{H}$ groups affect heterogeneous processing allowing a sufficient quantity of hydrogen to be oxidized (Mawhinney and Yates, 2001). A significant amount of carbonyl $\mathrm{C}=\mathrm{O}$ groups can create hydrophilic surface for water uptake, hygroscopic growth, and cloud droplets nucleation (Gustafsson et al., 2005; Popovicheva et al., 2008a, b).

Flares are used to burn excess flammable gases released during normal operating conditions or unplanned events in many industrial processes, such as oil-gas extraction, refineries, chemical plants, coal industry, and landfills (Fawole et al., 2016). Flaring emissions in Northern Siberia take place directly within the major low-altitude pathway of air masses penetrating into the Arctic (Popovicheva et al., 2017a) and, thus, have a disproportionally large contribution into the Arctic lower troposphere.

Numerous studies have been conducted to analyze the nanostructure, morphology, and composition of soot particles produced by combustion of gaseous hydrocarbons, fossil fuel, and biomass burning in a variety of different flame setups (Cain et al., 2010), in combustion chambers (Chen et al., 2004; Chakrabarty et al., 2006; Popovicheva et al., 2015d) and in engines at testing facilities (Popovicheva et al., 2017b). However, despite the importance of flaring, a challenge arises when dealing with real-sized flares for fundamental studies because inherent difficulties in sampling from an unconfined, turbulent, inhomogeneous, and elevated plume (Johnson et al., 2010). Moreover, the flame turbulence in diffusion flames is found to affect an emission factor (Sivathanu and Faeth, 1990); thus, variability in soot properties is likely.

A large lab-scale flare simulating the real-world conditions would help to clarify the soot properties. However, just a few studies are performed in laboratory-scale gas flares (Strosher, 2000; McEwen and Johnson, 2012; Conrad and Johnson, 2017), which addressed black carbon and gaseous emissions. Such simulations are complicated also by the incredibly wide range of operating conditions (flare diameters, exit velocities, and fuel compositions) encountered in different applications.

This paper describes a fundamental study of properties of particulate emission produced by a turbulent diffusion flame operated at conditions applicable for gas flaring practices using a range of representative gas mixtures $\left(\mathrm{N}_{2}, \mathrm{CO}_{2}\right.$, and $\mathrm{C} 1-\mathrm{C} 4$ hydrocarbons). In contrast to those studies that examine the properties of soot collected from different points within and above flames in order to assess the mechanism of soot formation (Fitzpatrick et al., 2007; Cain et al., 2010), we aim to characterize emitted soot to assess its environmental impacts. Several analytical techniques including HRTEM, SEM-EDX, and Raman and FTIR spectroscopy are used to analyze the gas flaring soot microstructure and composition. 


\section{MATERIALS AND METHODS}

\section{Small-scale Gas Flare}

Experiments were conducted in the Vertical Flare Facility in the Energy \& Emissions Research Laboratory at Carleton University; this consists of a vertical turbulent jet-diffusion burner and hooded sampling system described in details elsewhere. The burner sits beneath a large $(3.1 \mathrm{~m}$ included diameter) hexagonal exhaust hood that collects the entire exhaust plume and entrains dilution air into a steel duct that acted as a dilution tunnel in which the combustion products and entrained room air are drawn by the exhaust fan and mixed prior to being sampled. Two concentric perforated screens surround the flare to minimize the effects of room air currents while allowing air to freely entrain into the turbulent flame.

Fuels were mixed and delivered to the burner, and ejected from flare nozzles with exit diameters of $3.8,5.1$, and $7.6 \mathrm{~cm}$, thus putting the combustion in the "turbulent-buoyant" regime. The exit velocity at standard conditions $\left(0^{\circ} \mathrm{C}\right.$, $101.32 \mathrm{kPa}$ ) was varied from 0.5 to $1.5 \mathrm{~m} \mathrm{~s}^{-1}$. The fuel flow rates were corrected accordingly for each burner size, which resulted in a range of flow rates from 60.8 to $246.3 \mathrm{~L} \mathrm{~min}^{-1}$ (standard liters per minute at $0^{\circ} \mathrm{C}$ and $101.325 \mathrm{kPa}$ ). More details on the burner are shown in Kazemimanesh et al. (2019). Typical flares in Alberta, Canada (Johnson and Coderre, 2011), have burner inner diameters and exit velocities of $7.62-25.4 \mathrm{~cm}$ and $0.1-6 \mathrm{~m} \mathrm{~s}^{-1}$, respectively (McEwen and Johnson, 2012). These scales are somewhat larger than the conditions encountered in the lab, but similarly fall into the "turbulent-buoyant" regime in Delichatsios (1993). This research was focused on the quiescent wind conditions (i.e., zero cross-flow), which represents the "worst-case" scenario for soot production.

Gaseous fuel mixtures included the major chemical constituents of natural gases, methane $\left(\mathrm{CH}_{4}\right)$, ethane $\left(\mathrm{C}_{2} \mathrm{H}_{6}\right)$, propane $\left(\mathrm{C}_{3} \mathrm{H}_{8}\right)$, butane $\left(\mathrm{C}_{4} \mathrm{H}_{10}\right)$, nitrogen $\left(\mathrm{N}_{2}\right)$, and carbon dioxide $\left(\mathrm{CO}_{2}\right)$. The compositions of the tested gases mixtures, light ("L6"), medium ("M6"), and heavy ("H6"), are presented in Table 1. Additionally, a mixture of $97.5 \%$ methane and $2.5 \%$ butane, "MB," was used. Hydrocarbons higher than $\mathrm{C} 5$ as well as $\mathrm{He}$ and $\mathrm{H}_{2}$ were not included in the present test mixtures due to their generally lower concentrations in associated gas.

The three blends were created from the statistics of Alberta flare gas compositions. To create a light mixture, the $90^{\text {th }}$ percentile methane concentration was chosen as an upper bound, and the remaining fuel concentrations were based on their relative concentrations in the average fuel mixture (i.e., propane to ethane ratio, etc.). The heavy mixture was created in the same manner except that the $10^{\text {th }}$ percentile methane concentration was chosen as a lower bound. The heat of combustion estimated as an amount of the fuel burned at constant pressure and under standard conditions $\left(0^{\circ} \mathrm{C}\right.$ and 1 bar) per grams of fuel burned is characterized by Higher Heating Value (HHV), assuming that the heat contained in the water vapor is recovered. The gas mixtures presented in Table 1 are comparable to natural gas (34-45 $\left.\mathrm{MJ} \mathrm{m}^{-3}\right)$.

\section{Particle Sampling}

Flames of height up to $3 \mathrm{~m}$ were produced. Combustion products and entrained room air entered a hood and were drawn into an insulated dilution tunnel, which was vented to the atmosphere with a speed-controlled exhaust fan. A portion of this flow was further diluted from 2 to 5 times and carried into a smaller dilution tunnel from which samples for individual instruments were taken (details in Kazemimanesh et al., 2019).

The electrostatic precipitator (ESP) used was an ESPnano Model 100 (Dash Connector Technology, Inc.), which uses a high-voltage electrical field to simultaneously charge and collect airborne particles onto a substrate. The Thermophoretic Particle Sampler (TPS) developed at the University of British Columbia was used to collect samples. Both the ESP and TSP collected particles during 0.5-3 and 5-27 min of each burn, respectively. Collection flow rates were about 1.7 and $0.3 \mathrm{~L} \mathrm{~min}^{-1}$, respectively. Differences in the collection times are due to the properties of different collectors. The TPS allows the deposition of soot aerosols on a small area of about $1 \mathrm{~mm}^{2}$. Using the same collection time, electrostatic deposition shows loadings dispersed over the whole sample area, increasing the background signal of the substrate in some characterization techniques. Particles were deposited onto titanium substrates as well as lacey formvar/carbon copper TEM grid (200 mesh; Product No. 01881; Ted Pella). Titanium was selected as it is Raman inactive and it generates a stable background for EDX experiments. Lacey TEM grids were used for HRTEM analysis. For bulk analyses (which required higher sample mass), particles were collected on quartz fiber filters (Pall Life Sciences) with $25 \mathrm{~L} \mathrm{~min}^{-1}$ flow for 5-15 $\mathrm{min}$.

\section{Particle Characterization Techniques \\ Morphology}

Particle samples from this study were analyzed by SEM, combined with single particle compositional analysis described later. For detailed description of soot aggregate morphology and internal structure, a FEI Tecnai G2 HRTEM was used. Magnifications of up to $700 \mathrm{k} \times$ were achieved with a point resolution of $0.27 \mathrm{~nm}$ and a flexible high tension $(20,40,80,120,160$, and $200 \mathrm{kV})$. The images

Table 1. Hydrocarbon fuel mixtures used in present experiments based on typical flare compositions in Alberta, Canada (see Johnson and Coderre (2012)) shown in mole fraction. The higher heating value (HHV) is shown for each mixture.

\begin{tabular}{lllllllll}
\hline Fuel Mixture & Code & $\mathrm{CH}_{4}$ & $\mathrm{C}_{2} \mathrm{H}_{6}$ & $\mathrm{C}_{3} \mathrm{H}_{8}$ & $\mathrm{C}_{4} \mathrm{H}_{10}$ & $\mathrm{~N}_{2}$ & $\mathrm{CO}_{2}$ & $\mathrm{HHV}\left[\mathrm{MJ} \mathrm{m}{ }^{-3}\right]$ \\
\hline Light & $\mathrm{L} 6$ & 0.925 & 0.007 & 0.001 & 0.003 & 0.030 & 0.034 & 34.2 \\
Average & $\mathrm{M} 6$ & 0.866 & 0.058 & 0.026 & 0.022 & 0.019 & 0.009 & 40.2 \\
Heavy & $\mathrm{H} 6$ & 0.769 & 0.110 & 0.058 & 0.042 & 0.013 & 0.008 & 45.2 \\
\hline
\end{tabular}


were taken at approximately $500 \mathrm{k} \times$ with a tension of $300 \mathrm{kV}$. This system was also used to characterize the soot internal structure (below). In addition, primary particle size distributions and effective density were measured by other means, as reported in Kazemimanesh et al. (2019).

\section{Internal Structure}

Nine HRTEM images were studied: four M6 images, three L6 images, and two H6 images. To calculate the individual fringe length and tortuosity in soot nanostructure, the raw HRTEM images underwent a series of image processing steps resulting in a skeleton of graphene fringes, as described in Yehliu et al. (2011). The fringe length is calculated by adding the length of pixels in a given fringe skeleton while the tortuosity is the ratio between the fringe length and the distance between the endpoints of the fringe. The image processing algorithm does allow for parameter changes that affect the resulting fringe skeleton. The same default image analysis parameters are used for all images. Validation of the image processing algorithm was done with oxidized soot described in Sediako et al. (2017). More information on the validation process are shown in the Supplemental Information (SI).

Raman spectroscopy was also used to characterize the internal structure. We used a Renishaw confocal microscope with digital stage, with a laser of a $785 \mathrm{~nm}$ point focus and maximum power of $20 \mathrm{~mW}$ ( $1 \%$ of power used). The exposure and accumulation time were 1 and $10 \mathrm{~s}$, respectively. Three points for each sample were selected to collect Raman spectra. Before the deconvolution, the raw Raman spectra were smoothed by reducing the noise and then a wavelength range were selected, $500-2000 \mathrm{~cm}^{-1}$. To facilitate the peak fitting of the first-order Raman bands the baseline signal from the titanium substrate was subtracted. Raman spectra were fitted with an error analysis which employs the Levenberg-Marquardt algorithm. Five main peaks are encountered in the first order Raman spectrum of soot aerosols, as recommended by Sadezky et al. (2005), and all the peaks were fitted with a Lorentzian curve but the peak D3, which is fitted with a Gaussian curve. More information on the curve fitting is shown in the SI.

\section{Single Particle Elemental Composition}

For characterization of morphology and composition of individual particles, a Carl Zeiss LEO 1430 VP field emission SEM with a spatial resolution of $7 \mathrm{~nm}$ was used; the device was equipped with an Oxford INCA energy dispersive detector. Energy dispersive X-ray spectra for $Z$ elements $(Z \geq 5)$ were recorded in an SEM image mode, and the measured $X$-ray intensity was quantified to the elemental weight percent ( $w t \%$ ) with an accuracy of $0.3 \mathrm{wt} \%$. Samples were studied in high vacuum mode at $10 \mathrm{kV}$ and $1 \mathrm{nA}$.

The EDX analysis started with the collection of spectra from several areas of Ti foil substrates. No oxygen, metal, or mineral impurities were found, thus providing the background for sampled particle measurements. The analysis area of each sample was subdivided into a few fields to observe possible differences in particle composition. EDX analysis yielded a data matrix containing the weight concentrations for $\mathrm{C}, \mathrm{O}, \mathrm{N}, \mathrm{Ca}, \mathrm{Al}, \mathrm{Si}, \mathrm{S}, \mathrm{F}, \mathrm{Cl}, \mathrm{K}, \mathrm{Fe}, \mathrm{Ni}$, $\mathrm{Na}, \mathrm{Mg}$, and $\mathrm{Cr}$. Approximately 700 to 1000 individual particles were analyzed for each combustion condition, a number considered to be sufficient for a representative overview of elements and particle grouping in each sample (Xie et al., 2005; Chakrabarty et al., 2006; Popovicheva et al., 2012). About 12,000 particles were analyzed in the collected gas flaring samples.

Ambient aerosols affected by a large number of pollution sources are characterized by the internal mixture of carbonaceous matter, salt, and dust. With such complexity in individual particles, cluster analysis may be needed to separate groups of similar chemical composition (Van Borm and Adams, 1988; Popovicheva et al., 2017c). However, the particles examined in the present study are chemically more homogeneous; so, in this study we used routine statistical analyses of the particle composition. For particle grouping, a data matrix was sorted according to a given element abundance, starting from the most prominent. The group is formed from particles containing the chosen element at the highest amount, but not less than $3 \mathrm{wt} \%$. It was observed that the presence of more than $3 \mathrm{wt} \%$ in $\mathrm{C}$ - and $\mathrm{O}$-containing particles can change the morphology and the particle type from soot to mineral or salt. This approach was developed to identify particle types generated by different combustion sources.

The chemical characterization described above can be used to estimate the extent of hygroscopicity of particles using the methods developed previously (Popovicheva et al., 2008b; Kireeva et al., 2009). Particles are categorized as hydrophobic, hydrophilic, and hygroscopic, based on the amount of water uptake compared to reference laboratorymade soot with similar composition. The experimental approach for estimating the water absorbability as well as the concept of water uptake on soot is described elsewhere (Popovicheva et al., 2008a). For gas flaring soot analyses, a criteria for categorization can be extended using the approach for fossil fuel high-temperature combustion (Popovicheva et al., 2015b) and biomass burning (Popovicheva et al., 2016c), and utilization of a number of reference soots with known oxygen content. Graphitized soot (GTS) is used to represent hydrophobic adsorbents because of its well-characterized composition free from any impurities and perfect graphitized structure. Other reference soot aerosols were produced by the combustion of gaseous propane/butane fuel in a gas turbine engine combustor. Like flare soot, these particles are composed of agglomerates of roughly spherical primary particles with sizes between 20 and $50 \mathrm{~nm}$ with $\mathrm{O} / \mathrm{C}$ ratio up to $12 \%$. Previously this soot was used as the hygroscopic reference for the analysis of soot produced by diesel and aircraft engines (Kireeva et al., 2009).

\section{Chemical Functionalization}

Fourier transform infrared FTIR spectroscopy is used for a deeper analysis of soot chemical structure, based on the phenomenon where particular chemical bond can be vibrated by particular infrared (IR) radiation wavelength. FTIR spectra were collected with an IRPrestige-21 spectrometer 
(Shimadzu, Japan) in diffuse reflectance mode (DRS) using a ZnSe crystal in the range from 450 to $4000 \mathrm{~cm}^{-1}$ with a resolution of $4 \mathrm{~cm}^{-1}$. IR Solution software was applied to subtract the FTIR spectrum of blank substrates and correct the baseline absorbance. The range of $750-1250 \mathrm{~cm}^{-1}$ was not considered because of the strong absorption of the quartz filter material itself in this region. To address the possible inhomogeneity of the sample loading, spectra were collected from five different spots of each sample. If four out of five spectra demonstrated the same absorption bands, we considered these bands as the representative spectrum for the entire sample.

The FTIR spectrum is divided into the vibration band regions which are unique for each chemical compound. This process requires an extensive knowledge to identify the functional groups. Because of the possible overlapping of vibration bands, the functionality identification is accomplished through the use of the Shimadzu FTIR database and a set of authentic chemical standards measured in the same FTIR setup (Popovicheva et al., 2015c, 2017b), and applied in previous studies (Maria et al., 2002; Coury and Dillner, 2009).

\section{RESULTS AND DISCUSSION}

\section{Morphology}

Due to high temperatures, the decomposed fuel compounds have the enhanced molecular mobility at the flame front, which leads to formation of the spherical shape of primary particles (Wang, 2011). The SEM panorama of gas flaring soot shows the agglomerates of ultrafine primary particles containing from a few up to hundreds of spheres (Fig. 1(a)). The particle images for all flaring regimes studied outline a lace-like microstructure of chains composed from spherical particles (Figs. 1(b)-1(c)), which is a typical fractal-like structure for soot produced by high-temperature combustion (Daly and Horn, 2009). Primary particles as discrete spherules are randomly observed. Such multiple-scale topography is that of fractal agglomerate structure that offers a large specific surface area for water adsorption and chemical reactions (Popovitcheva et al., 2000). High-resolution images of primary particles representative for light-, medium-, and heavy-fuel mixture showed similar structures, independent of flare operating parameters (Fig. 2). Primary particle size was $30 \pm 10 \mathrm{~nm}$, consistent with the more extensive statistical studies reported by Kazemimanesh et al. (2019). These dimensions are similar to those observed in the emissions of diesel, residual oil, and coal combustion (Chen et al., 2005), of laboratory burners and jet turbine engine (Demirdjian et al., 2007; Saffaripour et al., 2017), which indicates a common nature of soot origin in high-temperature combustion. In contrast, the flaming phase of biomass burning produces larger primary particles $(\sim 90 \mathrm{~nm})$ as a result of pyrolytic oxidation for particle formation (Popovicheva et al., 2015d).

Nearly all particles emitted by the flare exhibited the typical fractal aggregate morphology expected for pure soot. This contrasts with emissions from many combustion sources. Solid irregular shapes of round, elongated morphology are frequently observed in engine exhausts contaminated by lubrication oil and engine wear (Popovicheva et al., 2014), in residual oil fly ashes (Chen et al., 2004), and in biomass burning due to condensation of potassium sulfates and chlorides evaporated from biomass (Popovicheva et al., 2015d). Low-temperature biomass burning shows strongly different morphology relating to quasi-spherical and tar particles (Chakrabarty et al., 2006).

\section{Internal Structure}

HRTEM images of gas flaring soot in our study show the curved light and dark lines around several growth centers (Fig. 2) relating to internal structure of small crystallites composed of several parallel planes of carbon atoms arranged in hexagonal arrays. Multiple spherical nuclei surrounded by several graphitic layers indicate that original small nuclei of primary particles coalesced together to form larger particles (Daly and Horn, 2009). Fig. 3 shows the trend of fringe length (a) and fringe tortuosity (b) that have been determined for various fuel mixtures. Fringe length and fringe tortuosity were not affected by the fuel mixture composition.

The Raman spectra show the well-known bands of D and $G$ peaks which are a clear signature of disordered and graphitic carbons respectively (Bladt et al., 2012). Soot is mainly composed of $\mathrm{sp}^{2}$-bonded carbon in strained, finite graphene domains, enclosed by $\mathrm{sp}^{3}$-bonded amorphous carbon. Gas flaring soot produced at different gas mixtures and operation conditions, collected with both TPS and ESP samplers, shows the $\mathrm{G}\left(1595 \mathrm{~cm}^{-1}\right)$ and $\mathrm{D}\left(1347 \mathrm{~cm}^{-1}\right)$ bands attributed to the carbon-carbon stretching vibrations (Fig. 4). The spectra shown here have not been corrected for the titanium background, and it is apparent that the effect is larger for the samples collected by ESP, possibly because ESP produces a thinner, less uniform deposit with more of the substrate exposed to the laser beam. A more detailed explanation of the Raman spectra deconvolution by five peak types is reported in the SI.

Raman spectra of soot can provide hints on the organic functional groups present in the collected aerosols (Ess et al., 2016). In the wavelength range between 500 and $2000 \mathrm{~cm}^{-1}$, the Raman spectra show an increased fluorescence background and an additional shoulder in the spectrum with increasing the organic content (Ess et al., 2016). For wavenumbers higher than $2000 \mathrm{~cm}^{-1}$, the organic content appears as a broad peak; this peak can identify oxidized PAHs. In Fig. 4, for Raman spectra of gas flaring soot, a few cases show a broader peak above the $2000 \mathrm{~cm}^{-1}$, although no correlation with the fuel mixture, flare velocity, and burner size has been found. Therefore, this broad peak has not been considered in the peak deconvolution.

In order to clarify the relationship between the flare operation conditions and graphitic disorder, Raman peak ratios for various fuel mixtures, D1/G (Fig. 5(a)), D2/G (Fig. 5(b)), D3/G (Fig. 5(c)), and D4/G (Fig. 5(d)), are examined. All bars shown in Fig. 5 are lower for heavier fuel conditions. Thus, heavier fuel mixtures generate soot with a higher disordered carbon content. D1/G, D2/G, D3/G, and $D 4 / G$ all decreases with an increase of the higher heating value of the fuel mixture. 


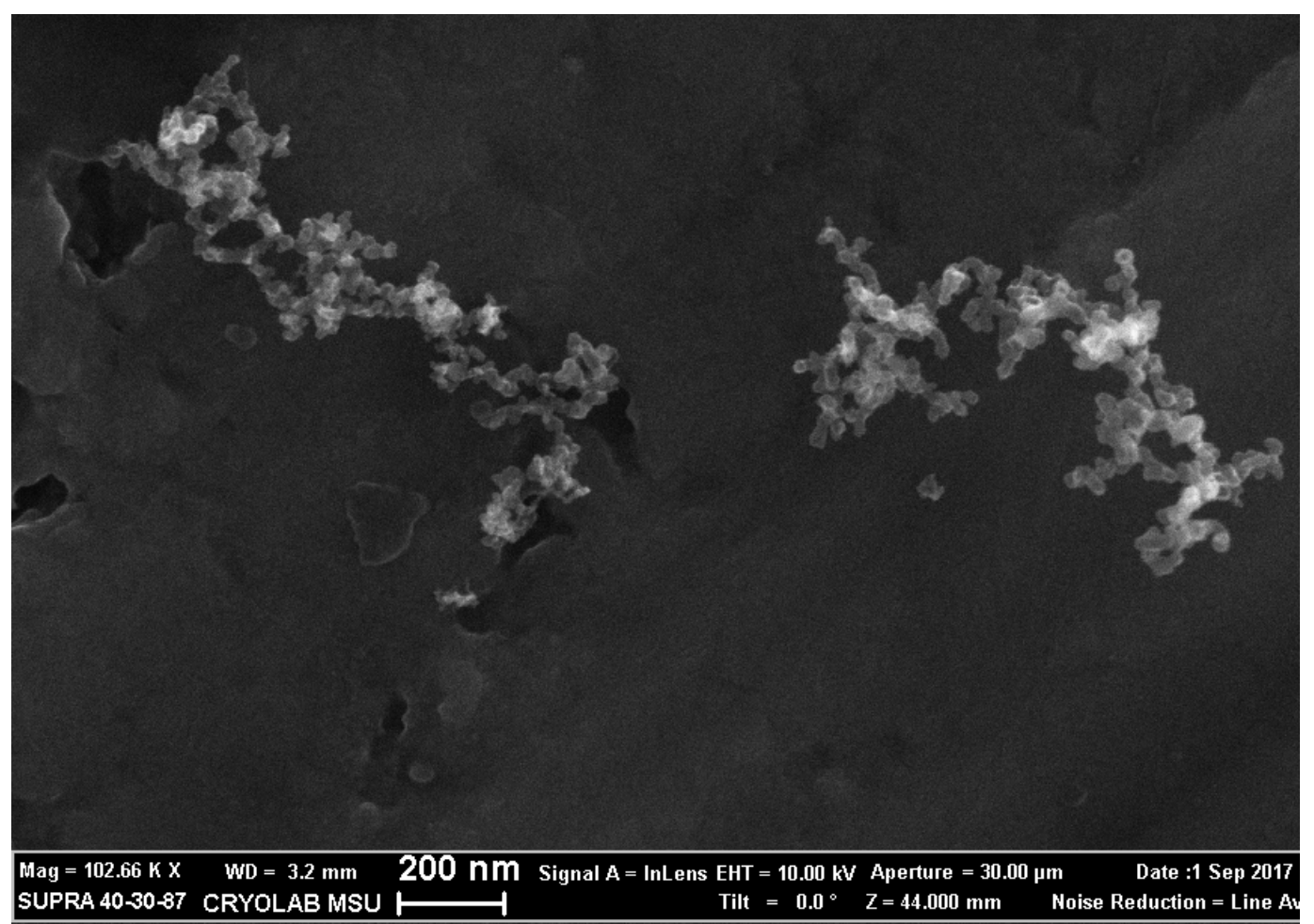

(a)

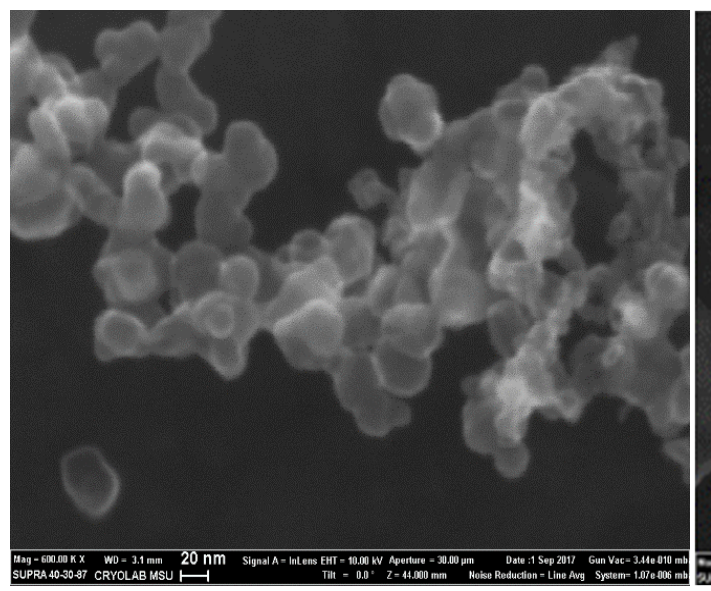

(b)

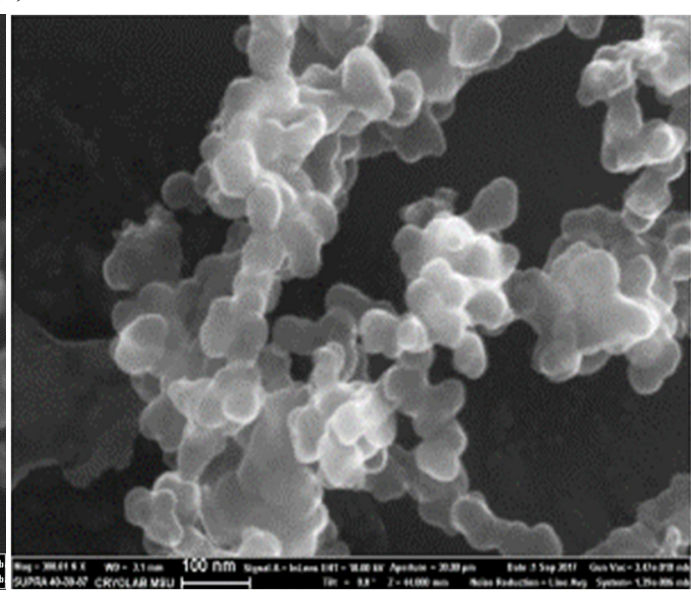

(c)

Fig. 1. (a) HRSEM panorama of gas flaring soot, and agglomerates of ultrafine primary particles in (b) L6, and (c) H6 smoke.
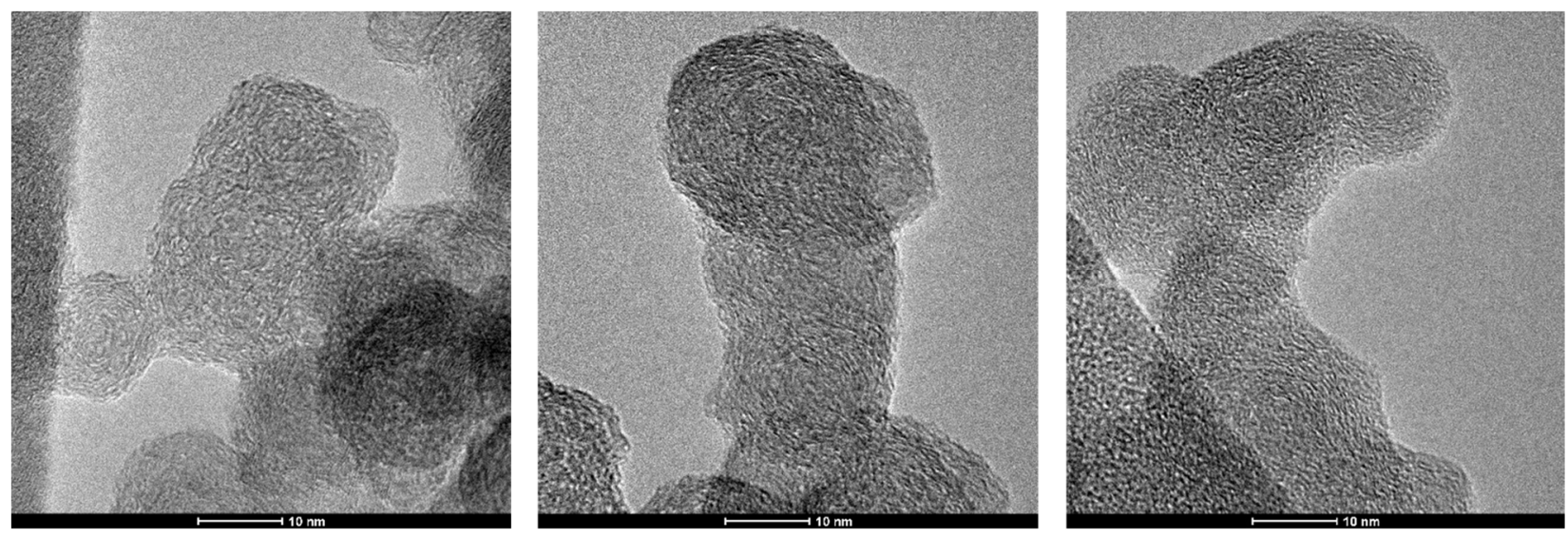

Fig. 2. Representative HRTEM images from left to right for light L6, medium M6, and heavy H6 hydrocarbon fuel mixture. 
(a)

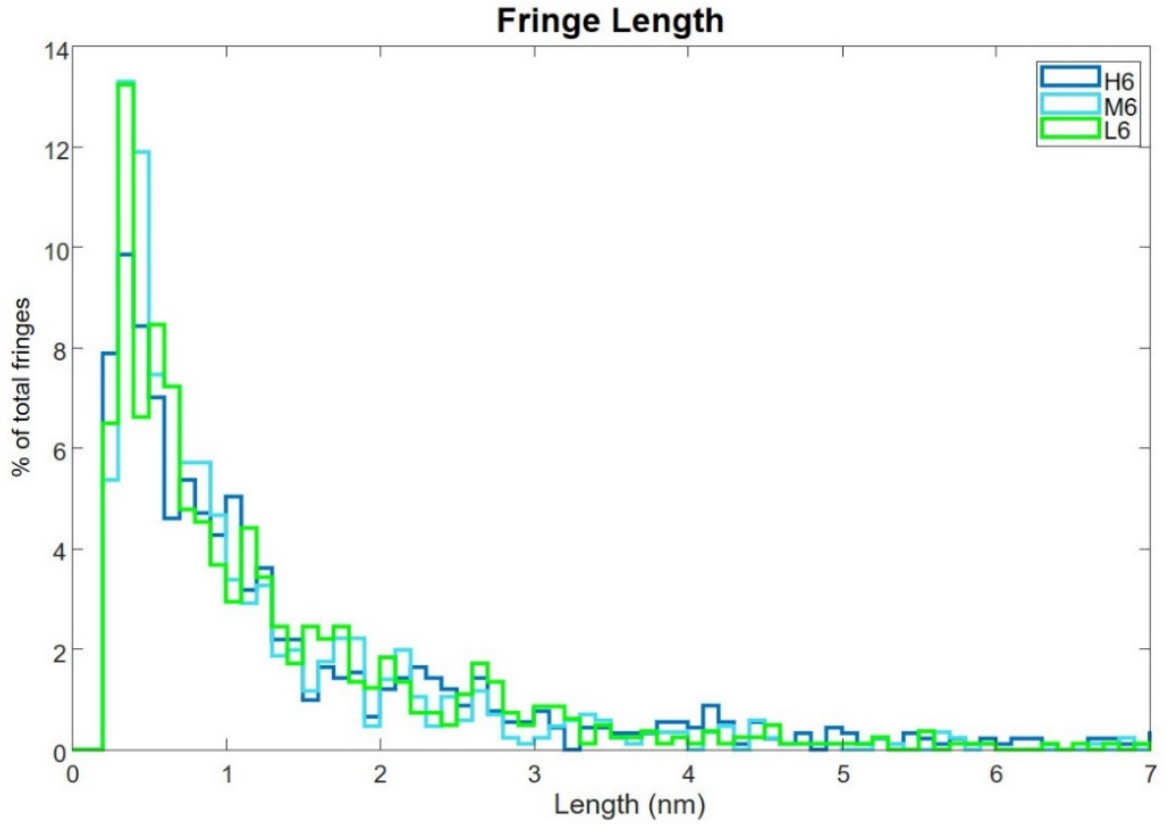

(b)

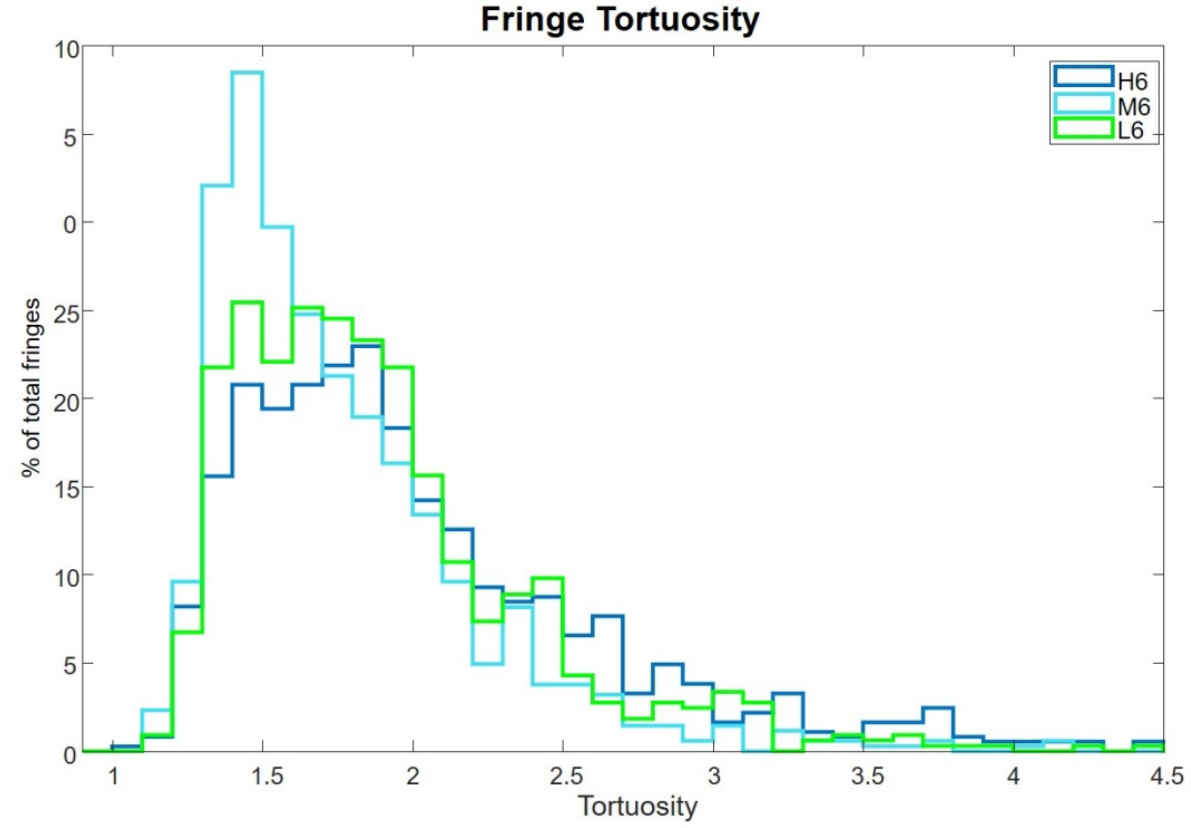

Fig. 3. Fringe (a) length and (b) tortuosityby the HRTEM analysis for L6, M6, and H6 fuel mixture.

The peak deconvolution has been strengthened by subtracting the titanium substrate spectrum rather than using a linear baseline subtraction. Using only a linear baseline subtraction, the $\mathrm{D} / \mathrm{G}$ ratios from the ESP samples were consistently very low relative to those from the TPS (Fig. 5). Using the Ti subtraction, the ratios for the ESP samples approach those of the TPS samples, but are still slightly lower. A reason considered was the effect of the corona discharge used in the ESP; a previous literature reference shows the impact of ozone emitted by the corona discharge to the soot crystallinity (Kuroki et al., 2010). Therefore, soot aerosols collected with a TPS were placed in an active ESP collector though which filtered air was passed. No major changes in any peak ratios have been found, showing that the corona discharge does not have any effect on the results, and any difference between the TPS and ESP samples should be attributed to the imperfect (though improved) baseline correction method.

$\mathrm{D} 1 / \mathrm{G}, \mathrm{D} 2 / \mathrm{G}, \mathrm{D} 3 / \mathrm{G}$, and $\mathrm{D} 4 / \mathrm{G}$ all decreases with an increase in the higher heating value of the fuel mixture, Fig. 5. Thus, as concluded by Kazeminanesh et al. (2019), heavier fuel mixtures generate higher graphitic soot. However, the results shown in Kazemimanesh et al. (2019) are obtained using the less sophisticated baseline subtraction applied only to the TPS samples. Here, the peak deconvolution has been strengthened by subtracting the titanium substrate spectra, bringing the results for the ESP samples and TPS samples into agreement. 


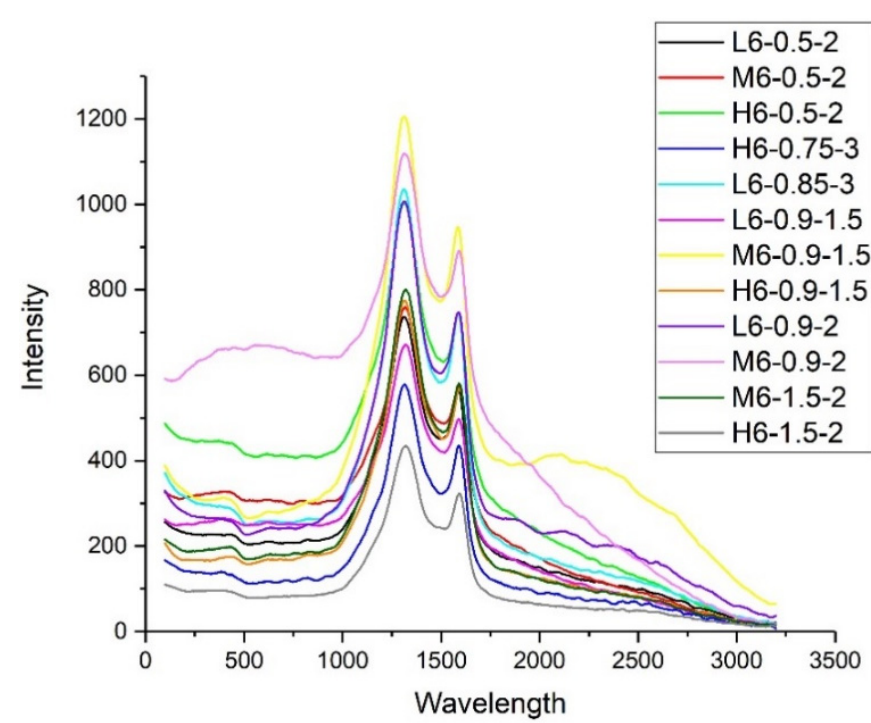

(a)

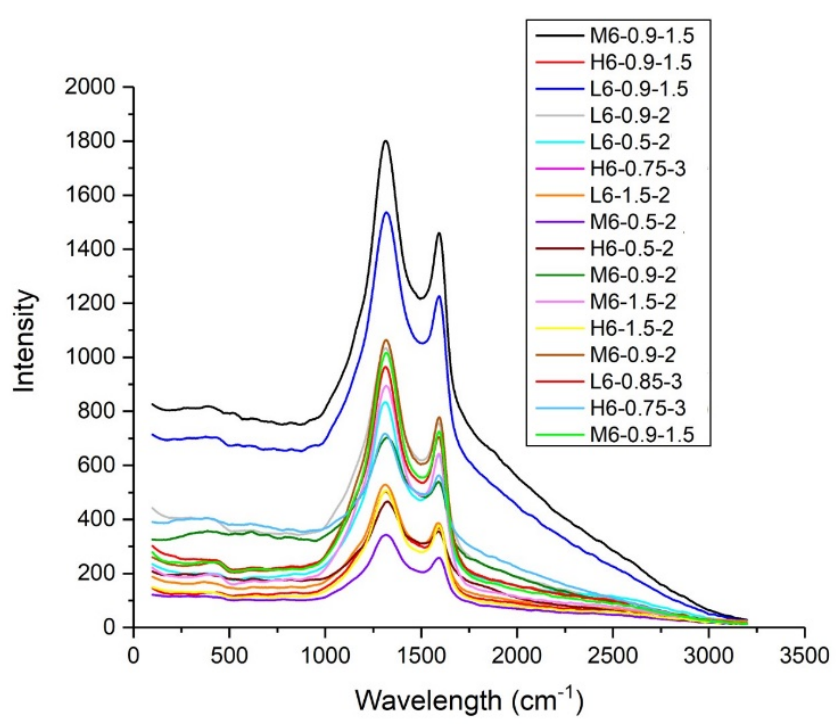

(b)

Fig. 4. Raman spectra of soot aerosols collected with (a) TPS and (b) ESP samplers. All the Raman spectra have been achieved by averaging three points from the same sample. The fuel mixtures, M6, L6, and H6, have been described in Table 1. The second number in the legend refers to the velocity at the burner exit of the flare, while the last number relates to the burner size.

\section{Single Particle Composition and Hygroscopicity}

The composition of individual gas flaring particles varied widely although carbon was (unsurprisingly) dominant. Fig. 6 shows the percentage of particles (out of 700-1000 particles per condition) containing the given elements. Nearly all particles contained carbon, but many also contained oxygen. The number of particles containing $\mathrm{Fe}, \mathrm{Cl}, \mathrm{Al}, \mathrm{Si}$, $\mathrm{F}, \mathrm{Cu}, \mathrm{Mn}, \mathrm{Co}, \mathrm{Cr}, \mathrm{V}$, and $\mathrm{Ni}$ was far lower and less consistent (Fig. 6). In up to $5 \%$ of particles, $\mathrm{Al}$ is found together with $\mathrm{Si}$, relating to composition of aluminosilicates in dust existing in background air during combustion experiments (Popovicheva et al., 2015d). Fe is present in a small percentage of particles produced at any fuel composition; it may be derived from the nozzle material due to flame impingement events or ambient dust. There is no correlation between the impurity abundance and combustion regime found for all nozzle diameters (for $5.1 \mathrm{~cm}$ chosen for Fig. 6 and for others).

Fig. 7 shows the average weight percent of elements in individual particles produced by flaring using L6, M6, and H6 fuel mixtures; $0.5,0.9$, and $1.5 \mathrm{~m} \mathrm{~s}^{-1}$ exit velocities; and $5.1 \mathrm{~cm}$ nozzle diameter. The most prominent feature is that carbon is dominant in the range from 79.6 up to $99.3 \mathrm{wt} \%$. Such comparably high $\mathrm{C}$ content was observed in ambient aerosols exclusively during high smoke period of intensive biomass burning (Popovicheva et al., 2016a).

Oxygen is present at $\sim 1 \%$ to $6.2 \%$ over the range of conditions, and there is no consistent trend with flare conditions. Significant variation is observed for the averaged weight composition of impurities in soot particles that confirms the occasional character of appearance of elements different from $\mathrm{C}$ and $\mathrm{O}$, either from the nozzle or dust in ambient air. The analysis of the element abundance over particles and of the weight percentage of each element in a whole range of regimes studied shows a higher frequency of impurity elements in samples collected by the ESP sampler. Since the collection time of ESP was significantly less than that of the TPS, we assume that TSP samples better represent the emission time and contaminations averaged over time. Therefore, the subsequent plots only include data from the TPS.

Table 2 presents four groups: "Elemental carbon," "Oxidized soot," "Al-Si-rich," and "Fe-rich" found for L6, M6, and H6 fuel mixtures; 0.5, 0.9, and $1.5 \mathrm{~m} \mathrm{~s}^{-1}$ exit velocities; and $5.1 \mathrm{~cm}$ nozzle diameter. Percentage of particles in each group (abundance) is shown in Fig. 8(a). Group "Elemental carbon" dominates and represents from $86 \%$ to $97 \%$ of particles. This group is composed of C only. Such group was found in laboratory-produced hydrocarbon soot (Bladt et al., 2012), in the exhaust of modern internal combustion engines using diesel and biofuel (Popovicheva et al., 2015a), and in flaming of pine wood (Popovicheva et al., 2015d) but at the significantly less abundance.

All particles that contain both $\mathrm{C}$ and $\mathrm{O}$, with less than $3 \mathrm{wt} \%$ of other elements, are placed in the group "Oxidized soot." This differs somewhat from results in previous studies of laboratory flame soot where measurable amounts of oxygen were present in a large fraction of the soot particles (Clague et al., 1999; Bladt et al., 2012). In diesel/biofuel exhaust, this group approaches up to $50 \%$ of all particles (Popovicheva et al., 2015a). For the flare particles, large levels of oxygen are concentrated in a small number of particles. Oxygen is concentrated in particles contained in the group "Oxidized soot" at much higher weight percent; however, this group shows a low abundance, just 3-5\% (Fig. 8(a)).

Approximately $1-5 \%$ of particles are in the group "Al-Sirich" (Fig. 8(a)). Around half of this group contains both Al and $\mathrm{Si}$ in aluminosilicates; the other half is rich in either $\mathrm{Si}$ 
(a)

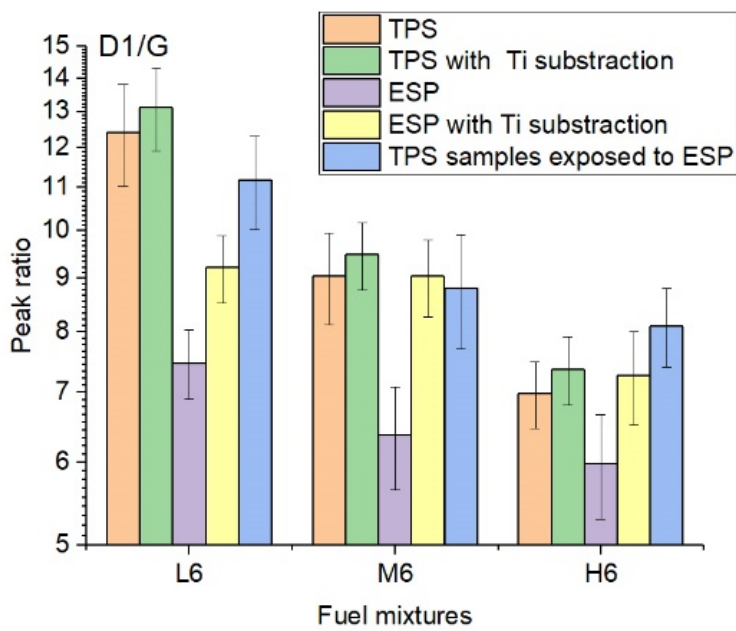

(c)

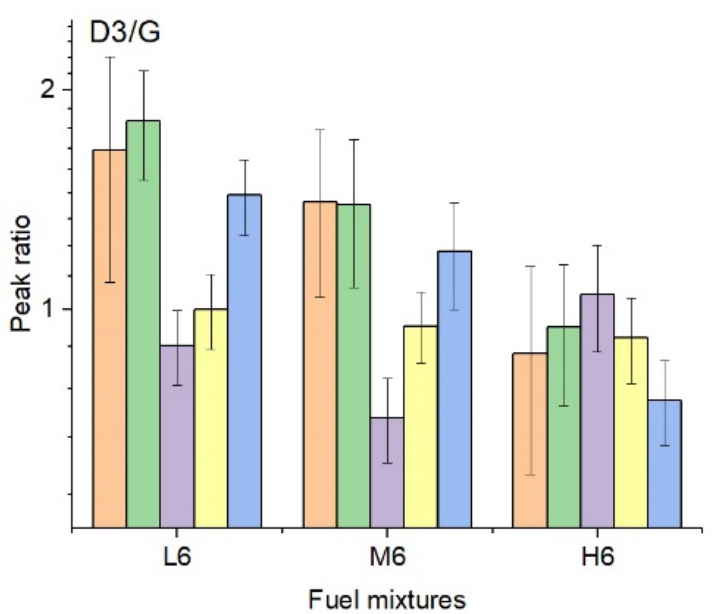

(b)

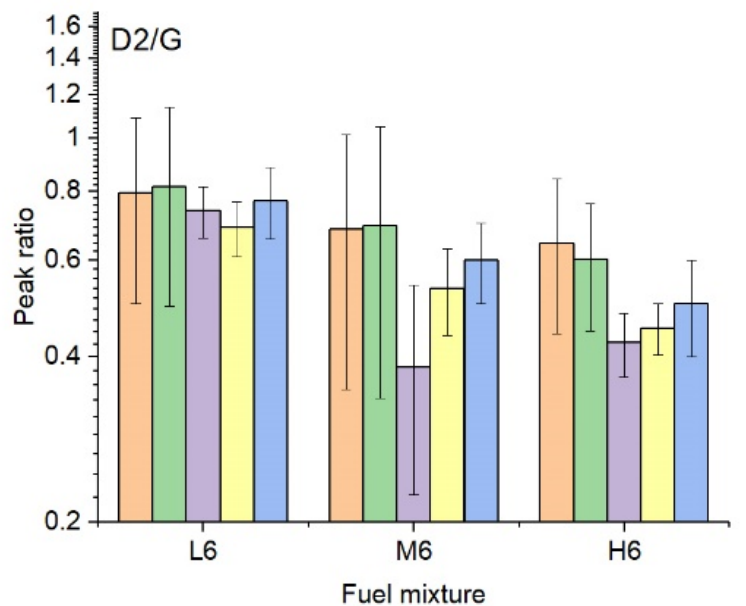

(d)

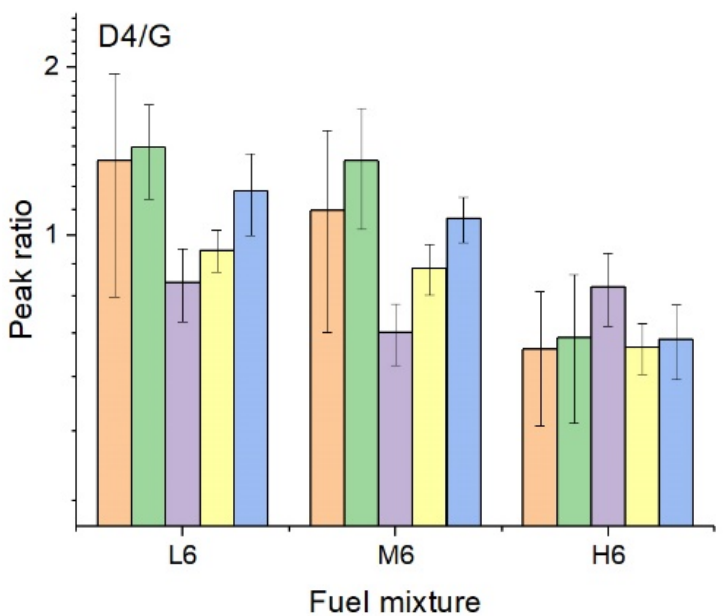

Fig. 5. Peak ratios (a) D1/G, (b) D2/G, (c) D3/G, and (d) D4/G, with the fuel mixtures, described in Table 1. Orange and purple bars show the Raman peak ratios of soot aerosols collected using a thermophoresis particle collector (TPS) and an electrostatic precipitator (ESP), respectively; green bars show the Raman peak ratios of soot aerosols collected using a TPS and by using in the deconvolution process the subtraction of the signal of samples substrate, which is titanium; the yellow bars show Raman peak ratios of soot aerosols collected by an ESP and by using in the deconvolution process the subtraction of the titanium signal; the blue bars show the Raman peaks of soot aerosols collected by a TPS and subsequently placed under an active ESP.

or Al. The appearance of group "Fe-rich" is not regular; it is observed for L6 and H6 fuel mixtures (Table 2). The weight percent of $\mathrm{Fe}$ in this group is high: $34-71 \%$, in some cases associated with $\mathrm{Cr}$ and $\mathrm{Ni}$, suggesting the presence of stainless steel. The flare nozzle might be the source of this, but ambient contamination cannot be ruled out.

The preceding particle characteristics can be used to determine the hygroscopicity of the samples (Koehler et al., 2009; Petters et al., 2009; Carrico et al., 2010). Three fractions of different elemental composition are separated. The group "Elemental carbon" and "Oxidized soot" comprise the $\mathrm{C}$ and $\mathrm{C}-\mathrm{O}$ fraction, respectively, while the $\mathrm{C}$ $\mathrm{O}-\mathrm{Al}-\mathrm{Si}-\mathrm{Fe}$ fraction is composed from both "Al-Si-rich" and "Fe-rich" of mineral impurities.

Negligible water absorption on GTS soot of $100 \%$ carbon composition observed in Popovicheva et al. (2010) shows the extreme hydrophobic (PHO) character of particles in the group "Elemental carbon." A propane/butane combustor soot with an $\mathrm{O} / \mathrm{C}$ higher than $12 \%$ is the reference criterion for soot hygroscopicity of particles in the $\mathrm{C}-\mathrm{O}$ fraction (Kireeva et al., 2009). The case of $\mathrm{O}$ wt\% lower than 12 relates to hydrophilic (PHI) particles. However, since in gas flaring particles of our study this case is not present, the group "Oxidized soot" should be addressed to a hygroscopic (SCOP) character. The "C-O-Al-Si-Fe fraction is composed of particles with no soluble elements like sulfur and potassium which were found in diesel exhaust and biomass burning and could be able to change the particle hygroscopicity significantly (Popovicheva et al., 2015b, 2016c). However, the $\mathrm{O} / \mathrm{C}$ ratio in the group "Al-Si-rich" and "Fe-rich" ranges from $20 \%$ to $50 \%$; therefore, particles in the C-O-Al-Si-Fe fraction can behave as SCOP. Hydrophobic and hygroscopic particles compose from $79.6 \%$ to $99.3 \%$ and from $3 \%$ to $13 \%$, respectively.

Hydrophobic particles in gas flaring dominate over hygroscopic ones. For comparison, soot particles collected 

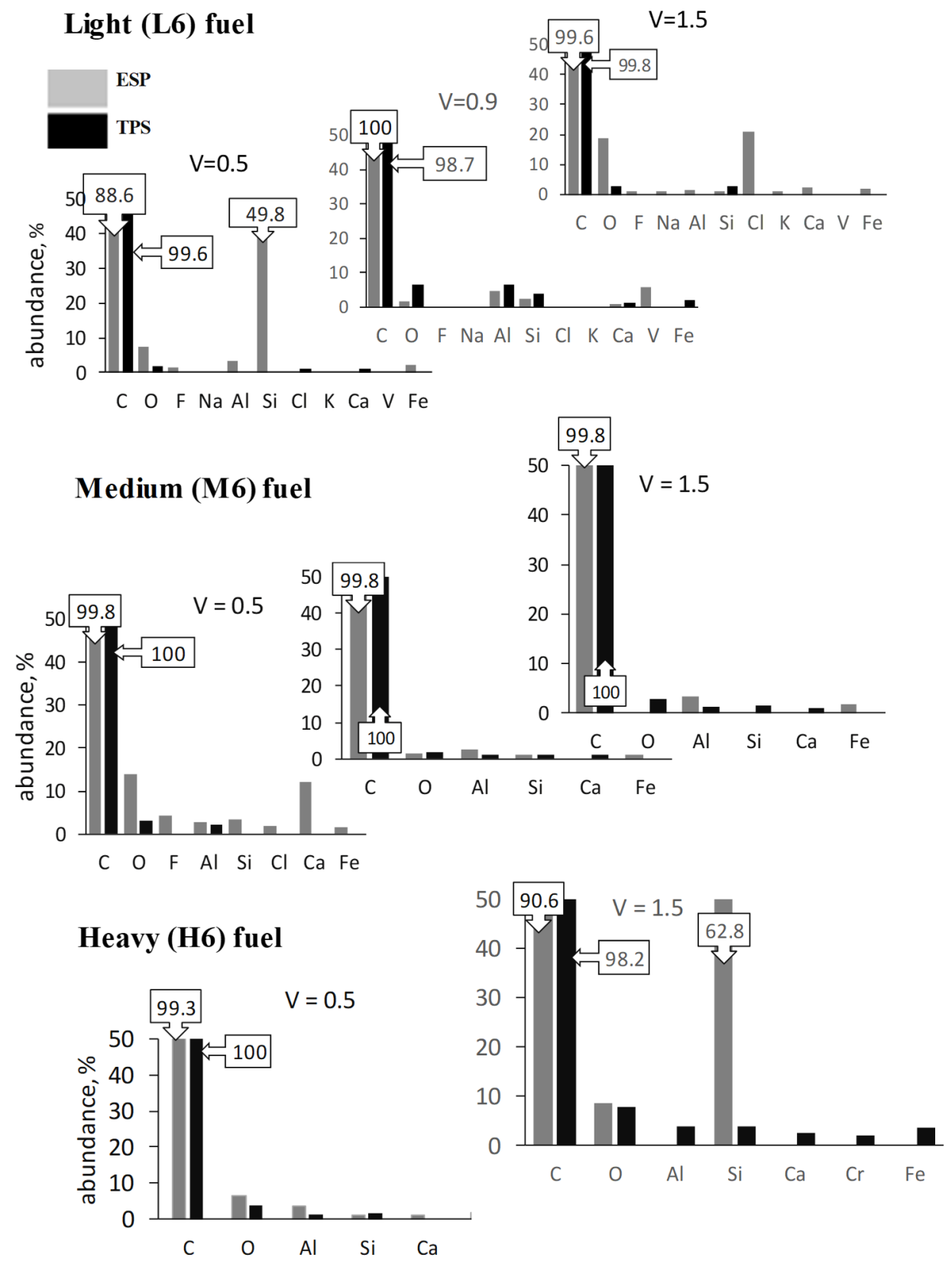

Fig. 6. Abundance of elements over particles produced by light (L6), medium (M6) and heavy (H6) fuel mixtures at exit velocities $\mathrm{V}=0.5,0.9$ and $1.5 \mathrm{~m} \mathrm{~s}^{-1}$ and nozzle diameter $5.1 \mathrm{~cm}$. Particles are collected by both ESP and TPS samplers.

behind an aircraft turbine, diesel, and ship engines were assigned into three fractions, C-O, C-O-S, and Fe-C-O (Kireeva et al., 2009; Popovicheva et al., 2015b). 41\% of particles from truck diesel engines were found to be hydrophobic and 54\% of them were separated into hydrophilic and hygroscopic because of oxygenated emissions containing water-soluble compounds (sulfates). Thus, because of more water-soluble impurities and a relatively homogeneous distribution of oxygen over particles, engine emissions are characterized by a higher extent of hygroscopicity.

\section{Chemical Functionalization}

Infrared spectra of the soot samples are shown in Fig. 9.
The most prominent bands of aromatic $\mathrm{C}=\mathrm{C}$ and aliphatic $\mathrm{C}-\mathrm{C}-\mathrm{H}$ groups are as expected. The vibrations at $1589 \mathrm{~cm}^{-1}$ can be attributed to $\mathrm{C}=\mathrm{C}$ stretching either in aromatic compounds or to microcrystalline structure of soot particles due to its polyaromatic character (Akhter et al., 1985; Fanning and Vannice, 1993). In both cases, the IR-inactive $\mathrm{C}=\mathrm{C}$ mode should be augmented by either sufficient asymmetry of the carbon material polyaromatic structure (e.g., by defects) or the presence of oxygen (Starsinic et al., 1983). The growth of this band is due to oxidation of carbons and was observed in Fanning and Vannice (1993). It was related to carbonyl group conjugated with aromatic segments (Sauvain and Rossi, 2016). Carbonyl $(\mathrm{C}=\mathrm{O})$ groups appear in gas flaring soot in many of the samples (Fig. 9). 


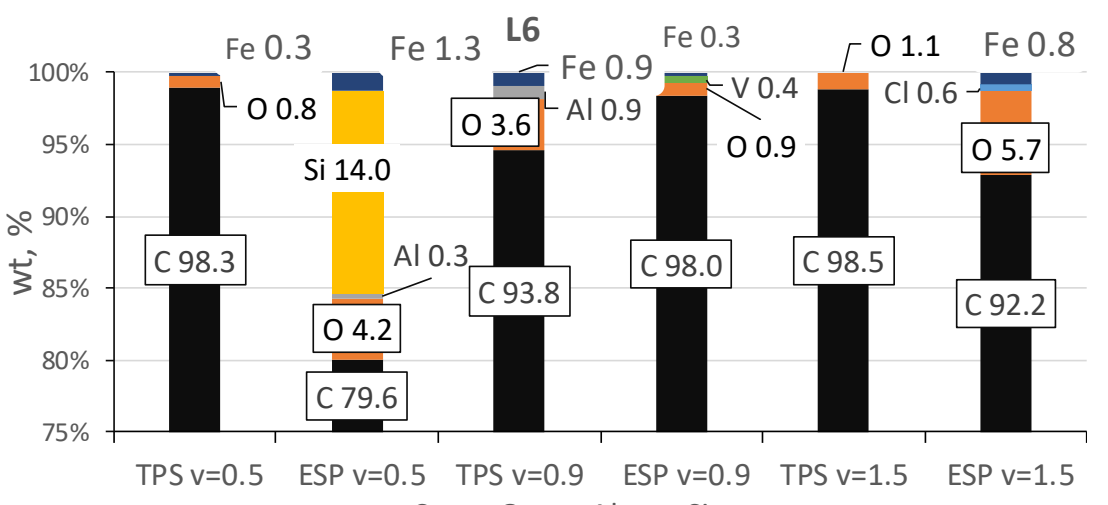

$\square \mathrm{C} \square \mathrm{O} \square \mathrm{Al} \square \mathrm{Si}$
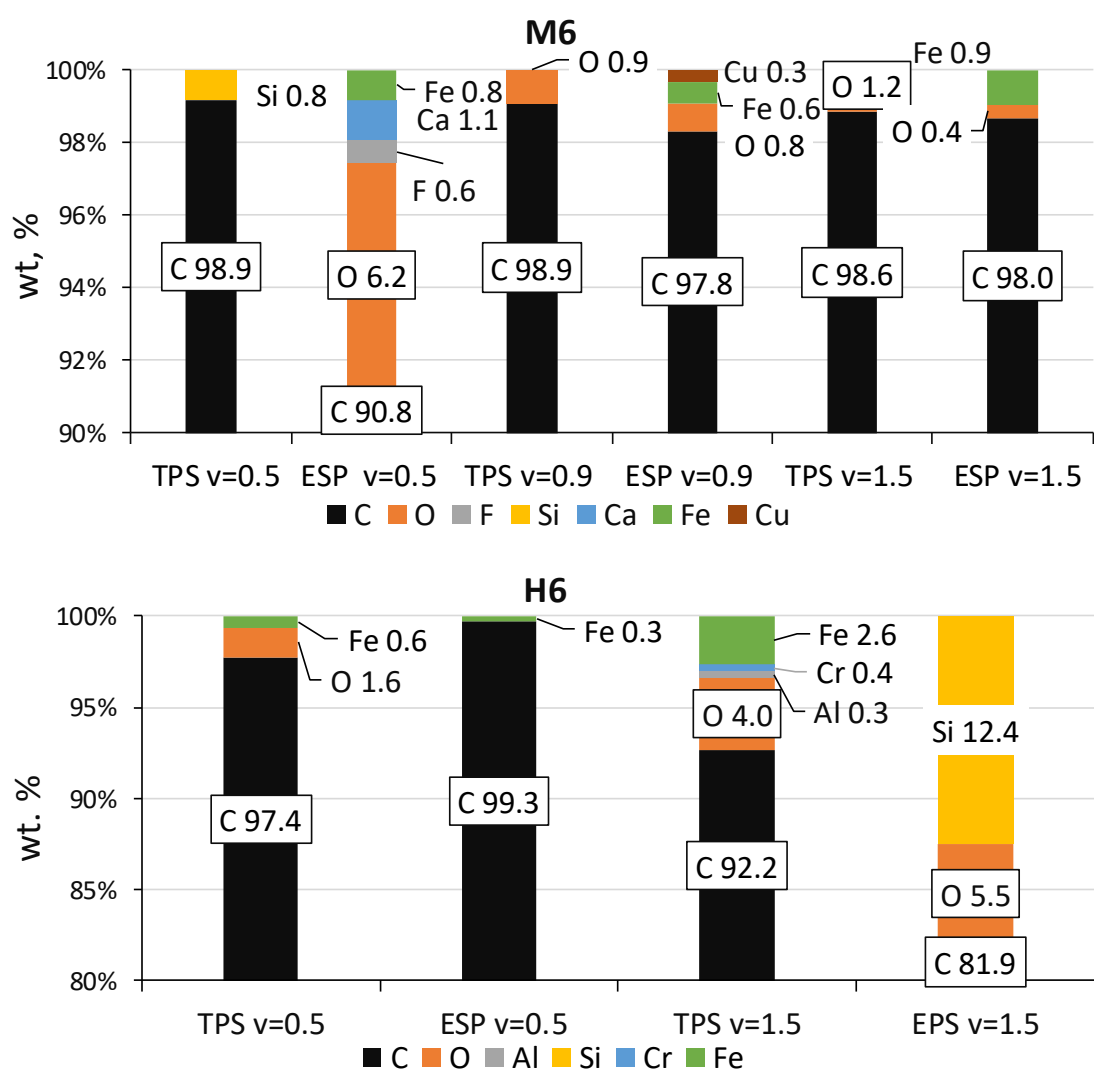

Fig. 7. The average weight percent of elements in individual particles produced by flaring used L6, M6, H6 fuel mixtures, exit velocities $\left(0.5,0.9,1.5 \mathrm{~m} \mathrm{~s}^{-1}\right)$, and $5.1 \mathrm{~cm}$ nozzle diameter. Particles are collected by both ESP and TPS samplers.

Bands peaked at 1807 and $1651 \mathrm{~cm}^{-1}$ are associated to anhydrides and aldehydes, respectively. Carboxyl [COO] and $\mathrm{C}=\mathrm{O}$ groups represent functionalities at 1668 and $1717 \mathrm{~cm}^{-1}$ in carboxylic acids and ketones. O-containing functionalities as a part of chemical structure make it hydrophilic, thus aiding absorption sites for water molecules (Kuznetsov et al., 2003). Their identification significantly improves the association between soot physiochemistry and CCN formation (Koehler et al., 2009). The prominent band at $1589 \mathrm{~cm}^{-1}$ in all samples indicates the similar chemical structure of gas flaring-produced particles, related to aromatic ring stretching mode enhanced in intensity by O-containing functional groups. Aromatic- $\mathrm{NO}_{2}$ groups $\left(1484 \mathrm{~cm}^{-1}\right)$ indicate the presence of oxy-nitrogen compounds.

The second prominent IR feature of aliphatic $\mathrm{C}-\mathrm{C}-\mathrm{H}$ vibrations in alkanes is observed at 2920 and $2860 \mathrm{~cm}^{-1}$ (Fig. 9). These two frequencies are associated with the strong asymmetric and symmetric stretches of methylene $\left(\mathrm{CH}_{2}\right)$ groups, respectively. An asymmetric stretch of methyl $\left(\mathrm{CH}_{3}\right)$ groups is randomly found at $2950 \mathrm{~cm}^{-1}$ as a weak shoulder of the stronger $\mathrm{CH}_{2}$ asymmetric stretch. The presence of the $\mathrm{C}-\mathrm{H}$ stretching in aliphatic groups can come from methylene groups bonded to aromatic rings on PAHs or methylene bridges (fluorine type) maintaining the interconnection of PAHs within graphitic structure (Santamaría et al., 2006).

Gas flaring particle structure demonstrates many graphitic cores surrounded by heterogeneous layers of shells spreading over the surface which could be produced from aliphatic components. For the tested conditions, various aliphatic to aromatic $\mathrm{C}-\mathrm{H}$ ratios do not show any relations 

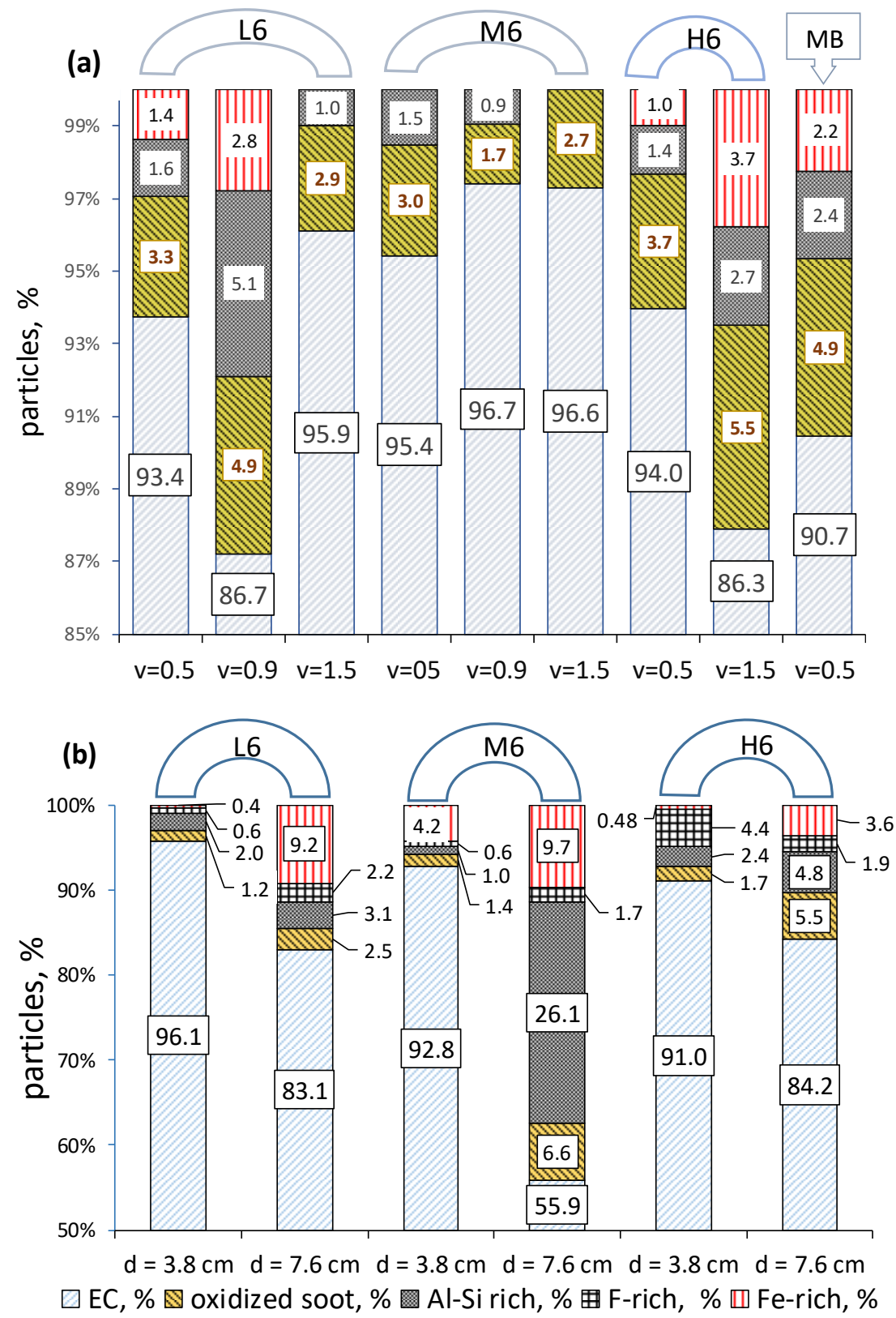

Fig. 8. Abundance of particles in Group "Elemental carbon" (EC), "Oxidized soot", "Al-Si- rich", "F-rich". and "Fe-rich" for L6, M6, H6, MB fuel mixtures and (a) exit velocities $\left(\mathrm{V}=0.5,0.9,1.5 \mathrm{~m} \mathrm{~s}^{-1}\right)$ at nozzle diameter $\mathrm{d}=5.1 \mathrm{~cm}$, and (b) V $=0.9$ at nozzle diameter $(3.8,7.6 \mathrm{~cm})$. Particles are collected by TPS sampler.

Table 2. Groups of particles, average composition of elements according to the fuel mixture and exit velocity at nozzle diameter of $5.1 \mathrm{~cm}$. Particles are collected by TPS sampler.

\begin{tabular}{llllll}
\hline \multirow{2}{*}{ fuel } & \multirow{2}{*}{$\mathrm{V}$} & \multicolumn{4}{c}{ Groups of particles } \\
\cline { 3 - 6 } & & Elemental carbon & Oxidized soot & $\mathrm{Al}-\mathrm{Si}$-rich & Fe-rich \\
\hline L6 & 0.5 & $\mathrm{C}_{100}$ & $\mathrm{C}_{53} \mathrm{O}_{46}$ & $\mathrm{C}_{87} \mathrm{Al}_{5} \mathrm{Si}_{5}$ & $\mathrm{C}_{45} \mathrm{O}_{9} \mathrm{Fe}_{46}$ \\
& 0.9 & $\mathrm{C}_{100}$ & $\mathrm{C}_{37} \mathrm{O}_{60}$ & $\mathrm{C}_{78} \mathrm{O}_{1} \mathrm{Al}_{17} \mathrm{Si}_{3}$ & $\mathrm{C}_{38} \mathrm{O}_{19} \mathrm{Fe}_{34} \mathrm{Ni}_{6} \mathrm{Cu}_{2}$ \\
\multirow{3}{*}{$\mathrm{M} 6$} & 1.5 & $\mathrm{C}_{100}$ & $\mathrm{C}_{61} \mathrm{O}_{38}$ & $\mathrm{C}_{80} \mathrm{Al}_{18} \mathrm{Si}_{2}$ & - \\
& 0.5 & $\mathrm{C}_{100}$ & $\mathrm{C}_{69} \mathrm{O}_{28}$ & $\mathrm{C}_{92} \mathrm{Al}_{7}$ & - \\
& 0.9 & $\mathrm{C}_{100}$ & $\mathrm{C}_{54} \mathrm{O}_{45}$ & $\mathrm{C}_{89} \mathrm{Al}_{6} \mathrm{Si}_{4}$ & - \\
$\mathrm{H} 6$ & 1.5 & $\mathrm{C}_{100}$ & $\mathrm{C}_{57} \mathrm{O}_{41}$ & - & - \\
& 0.5 & $\mathrm{C}_{100}$ & $\mathrm{C}_{53} \mathrm{O}_{46}$ & $\mathrm{C}_{89} \mathrm{Al}_{5} \mathrm{Si}_{5}$ & $\mathrm{C}_{45} \mathrm{O}_{9} \mathrm{Fe}_{46}$ \\
& 1.5 & $\mathrm{C}_{100}$ & $\mathrm{C}_{43} \mathrm{O}_{56}$ & $\mathrm{C}_{74} \mathrm{O}_{9} \mathrm{Al}_{10} \mathrm{Si}_{4}$ & $\mathrm{C}_{12} \mathrm{O}_{6} \mathrm{Fe}_{71} \mathrm{Cr}_{10}$ \\
\hline
\end{tabular}

${ }^{1}$ average element composition in $\mathrm{wt} \%$ with accuracy of $1 \%$. 



Fig. 9. FTIR spectra of gas flaring soot at various fuel mixture and operation conditions, described in Tables 1 and 2. Functionalities and band peaks are indicated.

or correlations with fuel mixture composition or operation conditions. This indicates a strong impact of gas-particle condensation of unburned volatiles released during the cooling and dispersion process on the chemical structure of particles collected from turbulent flame in a dilution tunnel. Small metal impurities observed in gas flaring particles can hardly influence the structure; a change of surface chemistry was observed in soot with Fe content more than 24\% (Bladt et al., 2012).

In diesel soot aerosols, the aliphatic C-C-H always accompanies aromatic $\mathrm{C}=\mathrm{C}$ functionalities demonstrating the basic chemical functionalized structure of hightemperature combustion particulates. $\mathrm{C}=\mathrm{C}$ vibrations are found in diesel particles produced by off-road diesel engines (Popovicheva et al., 2015c) and by modern on-road heavyduty engine using diesel and biofuels (Lapuerta et al., 2016; Popovicheva et al., 2017b). The impact of rapeseed oil as a fuel on the particle surface chemistry is indicated by $\mathrm{C}=\mathrm{O}$ groups (1705-1776 $\mathrm{cm}^{-1}$ ) in oxygenated compounds, in good agreement with observations of functionalities of biofuel particles emitted by an Opel Astra diesel engine (Popovicheva et al., 2014). Biomass pyrolysis is known to produce significant proportions of organic acids, phenol derivatives, and sugar derivatives, all of which are present in biomass smoke (Fitzpatrick et al., 2007; Popovicheva et al., 2016b).

\section{CONCLUSIONS}

We analyzed the gas flaring particulate emissions of a laboratory turbulent-buoyant jet diffusion flame, comparable in size to a small industrial flare and representative of flares in the upstream oil industry, while varying the sixcomponent methane-based fuel, the inner diameter of the burner, and the exit velocity.

The morphology of the emitted soot was characterized by fractal chains of agglomerates containing $30 \pm 10 \mathrm{~nm}$ primary particles with fullerenic multiple nuclei surrounded by several graphitic layers - a clear signature of carbon-carbon stretching vibrations generated by polyaromatic rings of small graphitic crystallites. Furthermore, the ratio of disordered to ordered carbon decreased as the heating value of the fuel mixture increased. 
Fuel combustion processes and interaction with oxidized products yielded aliphatic $\mathrm{C}-\mathrm{C}-\mathrm{H}$ groups combined with aromatic $\mathrm{C}=\mathrm{C}$ enhanced by oxygenated $\mathrm{C}=\mathrm{O}$ and $\mathrm{O}-\mathrm{H}$ functionalities. The high number of aliphatic $\mathrm{C}-\mathrm{H}$ groups is related to aliphatic shells extending over graphitic cores, indicating a combination of soot growth and the adsorption of volatiles on the particle surface during the cooling and dispersion of the exhaust.

The analysis of the composition of individual particles revealed an abundance of elemental carbon along with smaller amounts of oxidized soot, which is common with gas flaring due to high amounts of oxygen being concentrated in a small percentage of particles. Groups of impurities (dust aluminosilicates and iron oxide) were also produced irregularly at low levels. The presence of $\mathrm{Fe}$ in addition to $\mathrm{Ni}$ and $\mathrm{Cr}$ in the group "Fe-rich" indicated the possible consumption of oxygen due to the interaction between metal and carbon, the evaporation of burner inlet materials, and the catalytic oxidation process.

Once released into the atmosphere, gas flaring particles produced by pure fuel gas possess a large surface area for water adsorption. Quantifying the water uptake in our experiment revealed low hygroscopicity for particles emitted by small industrial flares fueled by a low hydrocarbon gas mixture. However, smoke enriched by oxygenated organic constituents in certain particles can act as efficient cloud condensation nuclei and sites for chemical reactions in the atmosphere. Therefore, further improvements in measuring gas-flaring emissions containing inorganic contaminants and environmentally dangerous compounds are necessary.

\section{ACKNOWLEDGEMENT}

Financial support from Flarenet and from the Russian Fund for Basic Research (RFBR) Project No. 180560084 is acknowledged, the methodology of FTIR analyses was developed under financial support of the RSF project No. 19-77-30004.

\section{SUPPLEMENTARY MATERIAL}

Supplementary data associated with this article can be found in the online version at http://www.aaqr.org.

\section{REFERENCES}

Akhter, M., Chughtai, A. and Smith, D. (1985). The structure of hexane soot I: Spectroscopic studies. Appl. Spectrosc. 39: 143-153.

Baldelli, A. and Rogak, S.N. (2019). Morphology and Raman spectra of aerodynamically classified soot samples. Atmos. Meas. Tech. Discuss. 12: 4339-4346.

Baumgardner, D., Popovicheva, O., Allan, J., Bernardoni, V., Cao, J., Cavalli, F., Cozic, J., Diapouli, E., Eleftheriadis, K. and Genberg, P. (2012). Soot reference materials for instrument calibration and intercomparisons: a workshop summary with recommendations Atmos. Meas. Tech. 5: 1869-1887.
Bladt, H., Schmid, J., Kireeva, E.D., Popovicheva, O.B., Perseantseva, N.M., Timofeev, M.A., Heister, K., Uihlein, J., Ivleva, N.P. and Niessner, R. (2012). Impact of Fe content in laboratory-produced soot aerosol on its composition, structure and thermo-chemical properties. Aerosol Sci. Technol. 46: 1337-1348.

Bond, T.C., Doherty, S.J., Fahey, D., Forster, P., Berntsen, T., DeAngelo, B., Flanner, M., Ghan, S., Kärcher, B. and Koch, D. (2013). Bounding the role of black carbon in the climate system: A scientific assessment. J. Geophys. Res. 118: 5380-5552.

Cain, J.P., Gassman, P.L., Wang, H. and Laskin, A. (2010). Micro-FTIR study of soot chemical compositionevidence of aliphatic hydrocarbons on nascent soot surfaces. Phys. Chem. Chem. Phys. 12: 5206-5218.

Carrico, C., Petters, M., Kreidenweis, S., Sullivan, A., McMeeking, G., Levin, E., Engling, G., Malm, W. and Collett, Jr, J. (2010). Water uptake and chemical composition of fresh aerosols generated in open burning of biomass. Atmos. Chem. Phys. 10: 5165-5178.

Chakrabarty, R.K., Moosmüller, H., Garro, M.A., Arnott, W.P., Walker, J., Susott, R.A., Babbitt, R.E., Wold, C.E., Lincoln, E.N. and Hao, W.M. (2006). Emissions from the laboratory combustion of wildland fuels: Particle morphology and size. J. Geophys. Res. 111: D07204.

Chen, L., Hu, X., Wang, J. and Yu, Y. (2019). Impacts of alternative fuels on morphological and nano-structural characteristics of soot emissions from an aviation piston engine. Environ. Sci. Technol. 53: 4667-4674.

Chen, Y., Shah, N., Huggins, F.E. and Huffman, G.P. (2004). Investigation of the microcharacteristics of $\mathrm{PM}_{2.5}$ in residual oil fly ash by analytical transmission electron microscopy. Environ. Sci. Technol. 38: 6553-6560.

Chen, Y., Shah, N., Braun, A., Huggins, F.E. and Huffman, G.P. (2005). Impacts of alternative fuels on morphological and nano-structural characteristics of soot emissions from an aviation piston engine. Energy Fuels 19: 1644-1651.

Clague, A., Donnet, J., Wang, T. and Peng, J. (1999). A comparison of diesel engine soot with carbon black. Carbon 37: 1553-1565.

Conrad, B.M. and Johnson, M.R. (2017). Field measurements of black carbon yields from gas flaring. Environ. Sci. Technol. 51: 1893-1900.

Coury, C. and Dillner, A.M. (2009). ATR-FTIR characterization of organic functional groups and inorganic ions in ambient aerosols at a rural site. Atmos. Environ. 43: 940-948.

Daly, H.M. and Horn, A.B. (2009). Heterogeneous chemistry of toluene, kerosene and diesel soots. Phys. Chem. Chem. Phys. 11: 1069-1076.

Delichatsios, M. (1993). Transition from momentum to buoyancy-controlled turbulent jet diffusion flames and flame height relationships. Combust. Flame 92: 349-364.

Demirdjian, B., Ferry, D., Suzanne, J., Popovicheva, O., Persiantseva, N. and Shonija, N. (2007). Heterogeneities in the microstructure and composition of aircraft engine combustor soot : Impact on the water uptake. J. Atmos. Chem. 56: 83-103. 
Ess, M., Ferry, D., Kireeva, E., Niessner, R., Ouf, F.X. and Ivleva, N. (2016). In situ Raman microspectroscopic analysis of soot samples with different organic carbon content: Structural changes during heating. Carbon 105: 572-585.

Fanning, P.E. and Vannice, M.A. (1993). A DRIFTS study of the formation of surface groups on carbon by oxidation. Carbon 31: 721-730.

Fawole, O.G., Cai, X.M. and MacKenzie, A. (2016). Gas flaring and resultant air pollution: A review focusing on black carbon. Environ. Pollut. 216: 182-197.

Fitzpatrick, E., Ross, A., Bates, J., Andrews, G., Jones, J., Phylaktou, H., Pourkashanian, M. and Williams, A. (2007). Emission of oxygenated species from the combustion of pine wood and its relation to soot formation. Process Saf. Environ. Prot. 85: 430-440.

Gustafsson, R., Orlov, A., Badger, C., Griffiths, P., Cox, R. and Lambert, R. (2005). A comprehensive evaluation of water uptake on atmospherically relevant mineral surfaces: DRIFT spectroscopy, thermogravimetric analysis and aerosol growth measurements. Atmos. Chem. Phys. 5: 3415-3421.

Gvakharia, A., Kort, E.A., Brandt, A., Peischl, J., Ryerson, T.B., Schwarz, J.P., Smith, M.L. and Sweeney, C. (2017). Methane, black carbon, and ethane emissions from natural gas flares in the Bakken Shale, North Dakota. Environ. Sci. Technol. 51: 5317-5325.

Hays, M.D. and Vander Wal, R.L. (2007). Heterogeneous soot nanostructure in atmospheric and combustion source aerosols. Energy Fuels 21: 801-811.

Huang, K. and Fu, J.S. (2016). A global gas flaring black carbon emission rate dataset from 1994 to 2012. Sci. Data 3: 160104.

Huang, K., Fu, J.S., Prikhodko, V.Y., Storey, J.M., Romanov, A., Hodson, E.L., Cresko, J., Morozova, I., Ignatieva, Y. and Cabaniss, J. (2015). Russian anthropogenic black carbon: Emission reconstruction and Arctic black carbon simulation. J. Geophys. Res. 120: 11306-311333.

Johnson, M.R., Devillers, R.W. and Thomson, K.A. (2010). Quantitative field measurement of soot emission from a large gas flare using sky-LOSA. Environ. Sci. Technol. 45: 345-350.

Johnson, M.R. and Coderre, A.R. (2012). Compositions and greenhouse gas emission factors of flared and vented gas in the Western Canadian Sedimentary Basin. J. Air Waste Manage. Assoc. 62: 992-1002.

Kazemimanesh, M., Dastanpour, R., Baldelli, A., Moallemi, A., Thomson, K.A., Jefferson, M.A., Johnson, M.R., Rogak, S.N. and Olfert, J.S. (2019). Size, effective density, morphology, and nano-structure of soot particles generated from buoyant turbulent diffusion flames. $J$. Aerosol Sci. 132: 22-31

Kireeva, E.D., Popovicheva, O.B., Persiantseva, N.M., Timofeyev, M.A. and Shonija, N.K. (2009). Fractionation analysis of transport engine-generated soot particles with respect to hygroscopicity. J. Atmos. Chem. 64: 129-147.

Koehler, K.A., DeMott, P.J., Kreidenweis, S.M., Popovicheva, O.B., Petters, M.D., Carrico, C.M., Kireeva,
E.D., Khokhlova, T.D. and Shonija, N.K. (2009). Cloud condensation nuclei and ice nucleation activity of hydrophobic and hydrophilic soot particles. Phys. Chem. Chem. Phys. 11: 7906-7920.

Kuroki, T., Ishidate, M., Okubo, M. and Yamamoto, T. (2010). Charge-to-mass ratio and dendrite structure of diesel particulate matter charged by corona discharge. Carbon 48: 184-190.

Kuznetsov, B., Rakhmanova, T., Popovicheva, O. and Shonija, N. (2003). Water adsorption and energetic properties of spark discharge soot: Specific features of hydrophilicity. J. Aerosol Sci. 34: 1465-1479.

Lapuerta, M., Rodríguez-Fernández, J., Sánchez-Valdepeñas, J. and Salgado, M. (2016). Multi-technique analysis of soot reactivity from conventional and paraffinic diesel fuels. Flow Turbul. Combust. 96: 327-341.

Maria, S.F., Russell, L.M., Turpin, B.J. and Porcja, R.J. (2002). FTIR measurements of functional groups and organic mass in aerosol samples over the Caribbean. Atmos. Environ. 36: 5185-5196.

Mawhinney, D.B. and Yates, Jr, J.T. (2001). FTIR study of the oxidation of amorphous carbon by ozone at $300 \mathrm{~K}$ Direct COOH formation. Carbon 39: 1167-1173.

McEwen, J.D. and Johnson, M.R. (2012). Black carbon particulate matter emission factors for buoyancy-driven associated gas flares. J. Air Waste Manage. Assoc. 62: 307-321.

Miller, A., Ahlstrand, G., Kittelson, D. and Zachariah, M. (2007). The fate of metal (Fe) during diesel combustion: Morphology, chemistry, and formation pathways of nanoparticles. Combust. Flame 149: 129-143.

Okada, K. and Hitzenberger, R.M. (2001). Mixing properties of individual submicrometer aerosol particles in Vienna. Atmos. Environ. 35: 5617-5628.

Petters, M.D., Carrico, C.M., Kreidenweis, S.M., Prenni, A.J., DeMott, P.J., Collett, J.L. and Moosmüller, H. (2009). Cloud condensation nucleation activity of biomass burning aerosol. J. Geophys. Res. 114: D22205.

Popovitcheva, O., Persiantseva, N., Trukhin, M., Rulev, G., Shonija, N., Buriko, Y.Y., Starik, A., Demirdjian, B., Ferry, D. and Suzanne, J. (2000). Experimental characterization of aircraft combustor soot: Microstructure, surface area, porosity and water adsorption. Phys. Chem. Chem. Phys. 2: 4421-4426.

Popovicheva, O., Persiantseva, N., Tishkova, V., Shonija, N. and Zubareva, N. (2008a). Quantification of water uptake by soot particles. Environ. Res. Lett. 3: 025009.

Popovicheva, O., Persiantseva, N.M., Shonija, N.K., DeMott, P., Koehler, K., Petters, M., Kreidenweis, S., Tishkova, V., Demirdjian, B. and Suzanne, J. (2008b). Water interaction with hydrophobic and hydrophilic soot particles. Phys. Chem. Chem. Phys. 10: 2332-2344.

Popovicheva, O., Persiantseva, N., Kireeva, E., Khokhlova, T. and Shonija, N. (2010). Quantification of the hygroscopic effect of soot aging in the atmosphere: Laboratory simulations. J. Phys. Chem. A 115: 298-306.

Popovicheva, O.B., Kireeva, E., Persiantseva, N., Timofeev, M., Bladt, H., Ivleva, N.P., Niessner, R. and Moldanová, J. (2012). Microscopic characterization of individual 
particles from multicomponent ship exhaust. J. Environ. Monit. 14: 3101-3110.

Popovicheva, O.B., Kireeva, E.D., Steiner, S., RothenRutishauser, B., Persiantseva, N.M., Timofeev, M.A., Shonija, N.K., Comte, P. and Czerwinski, J. (2014). Microstructure and chemical composition of diesel and biodiesel particle exhaust. Aerosol Air Qual. Res 14: 1392-1401.

Popovicheva, O., Engling, G., Lin, K.T., Persiantseva, N., Timofeev, M., Kireeva, E., Völk, P., Hubert, A. and Wachtmeister, G. (2015a). Diesel/biofuel exhaust particles from modern internal combustion engines: Microstructure, composition, and hygroscopicity. Fuel 157: 232-239.

Popovicheva, O.B., Engling, G., Lin, K.T., Persiantseva, N., Timofeev, M., Kireeva, E., Voelk, P., Hubert, A. and Wachtmeister, G. (2015b). Diesel/biofuel exhaust particles from modern internal combustion engines: Microstructure, composition, and hygroscopicity. Fuel 157: 232-239.

Popovicheva, O.B., Kireeva, E.D., Shonija, N.K., VojtisekLom, M. and Schwarz, J. (2015c). FTIR analysis of surface functionalities on particulate matter produced by off-road diesel engines operating on diesel and biofuel. Environ. Sci. Pollut. Res. 22: 4534-4544.

Popovicheva, O.B., Kozlov, V.S., Engling, G., Diapouli, E., Persiantseva, N.M., Timofeev, M., Fan, T.S., Saraga, D. and Eleftheriadis, K. (2015d). Small-scale study of Siberian biomass burning: I. Smoke microstructure. Aerosol Air Qual. Res 15: 117-128.

Popovicheva, O.B., Engling, G., Diapouli, E., Saraga, D., Persiantseva, N.M., Timofeev, M.A., Kireeva, E.D., Shonija, N.K., Chen, S.H., Nguyen, D.L., Eleftheriadis, K. and Lee, C.T. (2016a). Impact of smoke intensity on size-resolved aerosol composition and microstructure during the biomass burning season in Northwest Vietnam. Aerosol Air Qual. Res. 16: 2635-3654.

Popovicheva, O.B., Kozlov, V.S., Rakhimov, R.F., Shmargunov, V.P., Kireeva, E.D., Persiantseva, N.M., Timofeev, M.A., Engling, G., Elephteriadis, K., Diapouli, L., Panchenko, M.V., Zimmermann, R. and Kreis, J.S. (2016b). Optical-microphysical and physical-chemical characteristics of Siberian biomass burning: Experiments in Aerosol Chamber. Atmos. Oceanic Opt. 29: 492-500.

Popovicheva, O.B., Persiantseva, N.M., Timofeev, M.A., Shonija, N.K. and Kozlov, V.S. (2016c). Small-scale study of Siberian Biomass burning: II. smoke hygroscopicity. Aerosol Air Qual. Res. 16: 1558-1568.

Popovicheva, O.B., Evangeliou, N., Eleftheriadis, K., Kalogridis, A.C., Sitnikov, N., Eckhardt, S. and Stohl, A. (2017a). Black carbon sources constrained by observations in the Russian high arctic. Environ. Sci. Technol. 51: 3871-3879.

Popovicheva, O.B., Irimiea, C., Carpentier, Y., Ortega, I.K., Kireeva, E.D., Shonija, N.K., Schwarz, J., Vojtíšek-Lom, M. and Focsa, C. (2017b). Chemical composition of diesel/biodiesel particulate exhaust by ftir spectroscopy and mass spectrometry: Impact of fuel and driving cycle. Aerosol Air Qual. Res. 17: 1717-1734.
Popovicheva, O.B., Shonija, N.K., Persiantseva, N., Timofeev, M., Diapouli, E., Eleftheriadis, K., Borgese, L. and Nguyen, X.A. (2017c). Aerosol pollutants during agricultural biomass burning: A case study in Ba Vi Region in Hanoi, Vietnam. Aerosol Air Qual. Res. 17: 2762-2779.

Rebelo, S.L., Guedes, A., Szefczyk, M.E., Pereira, A.M., Araújo, J.P. and Freire, C. (2016). Progress in the Raman spectra analysis of covalently functionalized multiwalled carbon nanotubes: Unraveling disorder in graphitic materials. Phys. Chem. Chem. Phys. 18: 12784-12796.

Ross, A., Junyapoon, S., Jones, J., Williams, A. and Bartle, K. (2005). A study of different soots using pyrolysisGC-MS and comparison with solvent extractable material. J. Anal. Appl. Pyrolysis74: 494-501.

Russell, L.M., Bahadur, R. and Ziemann, P.J. (2011). Identifying organic aerosol sources by comparing functional group composition in chamber and atmospheric particles. Proc. Natl. Acad. Sci. U.S.A. 108: 3516-3521.

Sadezky, A., Muckenhuber, H., Grothe, H., Niessner, R. and Pöschl, U. (2005). Raman microspectroscopy of soot and related carbonaceous materials: Spectral analysis and structural information. Carbon 43: 1731-1742.

Saffaripour, M., Tay, L.L., Thomson, K.A., Smallwood, G.J., Brem, B.T., Durdina, L. and Johnson, M. (2017). Raman spectroscopy and TEM characterization of solid particulate matter emitted from soot generators and aircraft turbine engines. Aerosol Sci. Technol. 51: 518531.

Santamaría, A., Mondragón, F., Molina, A., Marsh, N.D., Eddings, E.G. and Sarofim, A.F. (2006). FT-IR and ${ }^{1} \mathrm{H}$ NMR characterization of the products of an ethylene inverse diffusion flame. Combust. Flame 146: 52-62.

Sediako, A.D., Soong, C., Howe, J.Y., Kholghy, M.R. and Thomson, M.J. (2017). Real-time observation of soot aggregate oxidation in an Environmental Transmission Electron Microscope. Proc. Combust. Inst. 36: 841-851.

Sivathanu, Y. and Faeth, G.M. (1990). Soot volume fractions in the overfire region of turbulent diffusion flames. Combust. Flame 81: 133-149.

Starsinic, M., Taylor, R.L., Walker, Jr, P.L. and Painter, P.C. (1983). Ftir studies of Saran chars. Carbon 21: 6974.

Stohl, A., Klimont, Z., Eckhardt, S., Kupiainen, K., Shevchenko, V.P., Kopeikin, V.M. and Novigatsky, A.N. (2013). Black carbon in the Arctic: The underestimated role of gas flaring and residential combustion emissions. Atmos. Chem. Phys. 13: 8833-8855.

Strosher, M.T. (2000). Characterization of emissions from diffusion flare systems. J. Air Waste Manage. Assoc. 50: 1723-1733.

Tumolva, L., Park, J.Y., Kim, J.S., Miller, A.L., Chow, J.C., Watson, J.G. and Park, K. (2010). Morphological and elemental classification of freshly emitted soot particles and atmospheric ultrafine particles using the TEM/EDS. Aerosol Sci. Technol. 44: 202-215.

Trivanovic, U., Corbin, J.C., Baldelli, A., Peng, W., Yang, J., Kirchen, P., Miller, J.W., Lobo, P., Gagné, S. and Rogak, S.N. (2019). Size and morphology of soot 
produced by a dual-fuel marine engine. J. Aerosol Sci. 138: 105448.

Van Borm, W.A. and Adams, F.C. (1988). Cluster analysis of electron microprobe analysis data of individual particles for source apportionment of air particulate matter. Atmos. Environ. 22: 2297-2307.

Wang, H. (2011). Formation of nascent soot and other condensed-phase materials in flames. Proc. Combust. Inst. 33: 41-67.

Weyant, C.L., Shepson, P.B., Subramanian, R., Cambaliza, M.O., Heimburger, A., McCabe, D., Baum, E., Stirm, B.H. and Bond, T.C. (2016). Black carbon emissions from associated natural gas flaring. Environ. Sci. Technol. 50: 2075-2081.
Xie, R., Seip, H., Leinum, J., Winje, T. and Xiao, J. (2005). Chemical characterization of individual particles $\left(\mathrm{PM}_{10}\right)$ from ambient air in Guiyang City, China. Sci. Total Environ. 343: 261-272.

Yehliu, K., Vander Wal, R.L. and Boehman, A.L. (2011). Development of an HRTEM image analysis method to quantify carbon nanostructure. Combust. Flame 158: 1837-1851.

Received for review, May 1, 2019

Revised, July 22, 2019

Accepted, August 31, 2019 